\title{
Evaluation of the HadGEM3-A simulations in view of detection and attribution of human influence on extreme events in Europe
}

Article

Accepted Version

Vautard, R., Christidis, N., Ciavarella, A., Alvarez-Castro, C., Bellprat, O., Christiansen, B., Colfescu, I., Cowan, T., DoblasReyes, F., Eden, J., Hauser, M., Hegerl, G., Hempelmann, N., Klehmet, K., Lott, F., Nangini, C., Orth, R., Radanovics, S., Seneviratne, S. I., van Oldenborgh, G. J., Stott, P., Tett, S., Wilcox, L. and Yiou, P. (2019) Evaluation of the HadGEM3-A simulations in view of detection and attribution of human influence on extreme events in Europe. Climate Dynamics, 52 (1-2). pp. 1187-1210. ISSN 0930-7575 doi:

https://doi.org/10.1007/s00382-018-4183-6 Available at https://centaur.reading.ac.uk/76175/

It is advisable to refer to the publisher's version if you intend to cite from the work. See Guidance on citing.

To link to this article DOI: http://dx.doi.org/10.1007/s00382-018-4183-6

Publisher: Springer 
including copyright law. Copyright and IPR is retained by the creators or other copyright holders. Terms and conditions for use of this material are defined in the End User Agreement.

\section{www.reading.ac.uk/centaur}

\section{CentAUR}

Central Archive at the University of Reading

Reading's research outputs online 
1 Evaluation of the HadGEM3-A simulations in view of 2 detection and attribution of human influence on extreme 3 events in Europe

4

Robert Vautard (1), Nikolaos Christidis (2), Andrew Ciavarella (2), Carmen Alvarez-Castro (1), Omar Bellprat (3), Bo Christiansen (4), loana Colfescu (5), Tim Cowan (5), Francisco Doblas-Reyes (3), Jonathan Eden (6), Mathias Hauser (7) Gabriele Hegerl (5), Nils Hempelmann (1), Katharina Klehmet (8), Fraser Lott (2), Cathy Nangini (1), René Orth (7), Sabine Radanovics (1), Sonia I. Seneviratne (7), Geert Jan van Oldenborgh (6), Peter Stott (2), Simon Tett (5), Laura Wilcox (9), Pascal Yiou (1)

(1) Laboratoire des Sciences du Climat et de l'Environnement, Institut Pierre-Simon Laplace, Université

(2) UK Met Office Hadley Centre, FitzRoy Road, Exeter EX1 3PB, UK

(3) Barcelona Supercomputing Center, Barcelona, Spain

(4) Danish Meteorological Institute, Copenhagen, Denmark

(5) School of GeoSciences, University of Edinburgh, Edinburgh EH9 3JW, UK

(6) Royal Netherlands Meteorological Institute (KNMI), De Bilt, Netherlands

(7) Institute for Atmospheric and Climate Science, ETH Zurich, Zurich, Switzerland

(8) Institute of Coastal Research, Helmholtz-Zentrum Geesthacht, Geesthacht, Germany 
22

23

\section{Abstract}

A detailed analysis is carried out to assess the HadGEM3-A global atmospheric model skill in simulating extreme temperatures, precipitation and storm surges in Europe in the view of their attribution to human influence. The analysis is performed based on an ensemble of 15 atmospheric simulations forced with observed Sea Surface Temperature of the 54 year period 1960-2013. These simulations, together with dual simulations without human influence in the forcing, are intended to be used in weather and climate event attribution. The analysis investigates the main processes leading to extreme events, including atmospheric circulation patterns, their links with temperature extremes, landatmosphere and troposphere-stratosphere interactions. It also compares observed and simulated variability, trends and generalized extreme value theory parameters for temperature and precipitation.

One of the most striking findings is the ability of the model to capture North-Atlantic atmospheric weather regimes as obtained from a cluster analysis of sea level pressure fields. The model also reproduces the main observed weather patterns responsible for temperature and precipitation extreme events. However, biases are found in many physical processes. Slightly excessive drying may be the cause of an overestimated summer interannual variability and too intense heat waves, especially in central/northern Europe. However, this does not seem to hinder proper simulation of summer temperature trends. Cold extremes appear well simulated, as well as the underlying blocking frequency and stratosphere-troposphere interactions . Extreme precipitation amounts are overestimated and too variable. The atmospheric conditions leading to storm surges were also examined in the Baltics region. There, simulated weather conditions appear not to be leading to strong enough storm surges, but winds were found in very good agreement with reanalyses. The performance in reproducing atmospheric weather patterns indicates that biases mainly originate from local and regional physical processes. This makes local bias adjustment meaningful for climate change attribution. 


\section{Introduction}

In recent years attribution of changing likelihood of weather events has motivated an outstanding effort of the climate science community (Stott et al., 2016). While detecting trends in odds of extreme events (eg. as characterized by the exceedance of a threshold) can draw solely on observational data, formal attribution to human activities requires comparing statistics in a "current climate" world and in a world where human activities have not occurred. This requires model simulations with different sets of assumptions concerning external forcing. This also requires that the models used are able to simulate the changes in likelihood of extremes by comparing with observations, which is often difficult in practice due to the short length and lack of homogeneity of observational data sets. A simplification is often made with the assumption that the anthropogenic effect is included in surface variables such as SST, sea ice (Pall et al., 2011) or soil moisture (Hauser et al., 2016), and in atmospheric composition, and that extreme events respond to this influence through processes linking surface and atmosphere. In contrast, attribution of observed trends to causes relies on analysis of the observed change with the help of climate models, hence is more directly anchored to the observed change (see NAS report, 2016; Hegerl and Zwiers, 2011). In practice, anthropogenic forcing influence on temperature-related variables is such that changes are found with a high consistency using both approaches for trends in mean and extremes (Bindoff et al., 2013).

Attribution makes one unavoidable assumption: that dynamical and physical processes are correctly represented in the climate model used for attribution. If all processes are well accounted for, sensitivities to forcing changes should be realistic. Attribution of weather events therefore requires a careful evaluation of processes involved in the build-up of the events. Evaluation also requires examination of extreme events statistics, and if possible their change with increasing greenhouse gases and other human-driven changes (Bellprat and Doblas-Reyes, 2016; Lott and Stott, 2016; Sippel et al., 2016). 
This study examines how the newly upgraded Hadley Centre Global Environmental Model version 3Atmosphere (HadGEM3-A) atmospheric model performs in view of event attribution in Europe, with a focus on processes leading to extreme events. The earlier, lower resolution, version of the model was employed in several attribution studies of extreme events including consecutive cold winters in the UK, the Moscow heatwave in July 2010 (Christidis et al., 2013a), the severe East African drought of 2011 (Lott et al., 2013), the Eastern Australia floods of 2011 (Christidis et al., 2013b) and the cold spring of 2013 in the UK (Christidis et al., 2014). These analyses quantified the effect of anthropogenic influence on the likelihood of the events as well as the associated uncertainty from limited number of available simulations. Moreover, simple evaluation assessments were carried out to demonstrate that the model was fit for purpose and able to realistically represent the type of extremes under consideration in the region of interest. Angelil et al. (2016) compared the simulated extreme events with reanalyses datasets at relatively high resolution and found mismatches among all sets (models and reanalyses and among reanalyses themselves). This highlights observational difficulties when comparing sub-regional trends using reanalyses, and emphasizes the need to not only evaluate statistical properties but also physical mechanisms involved in the trends.

Here, the new ensemble of simulations is evaluated through comparison with available observations. These simulations are now used in several attribution studies (e.g. Eden et al, 2016; van Oldenborgh et al., 2017, in preparation; Philip et al., 2017, Hauser et al, 2017, Klehmet et al, 2017, in preparation, Eden et al, 2017, Christiansen et al, 2017, in preparation, Wilcox et al., 2017), where evaluation is carried out for the local case study. However, an overall evaluation of the model for Europe is necessary in order to assess confidence in attribution results derived from this model.

This article addresses three main questions: (i) are the simulations correctly representing the statistics of events for the historical period 1960-2013? (ii) Are the simulations correctly representing long-term changes in extreme events and dynamics along the reference period? (iii) Are the simulations correctly representing the key processes driving to extreme events? 
The first and last issues are covered in detail in this document. The second one is a more difficult question to address with 54-year long simulations. Trends, especially in extremes, have regional patterns of response to human activities that are fairly uncertain due to long-term atmospheric variability. Hence a single-realization observation is not expected to agree completely with model simulations.

A last issue concerning the model ensemble is also whether the overall ensemble also captures the natural variability well. This will however not be considered here to keep focus on processes. This question was addressed in a theoretical framework to show that the consistency of the ensemble spread can be measured by the notion of reliability (Bellprat and Doblas-Reyes, 2016; Lott and Stott, 2016). Ensemble reliability measures whether the probability to exceed a threshold (e.g. an extreme event or a large model quantile) agrees with the frequencies of the same threshold in an observed record. Correct reliability is therefore a necessary condition for the ensemble probabilities used in event attribution studies not to be biased. A bias in ensemble reliability systematically affects the fraction of attributable risk (Bellprat and Doblas-Reyes, 2016).

We focus here on a few types of events and processes to give an overview of the performance of the HadGEM3-A system in Europe. The evaluation does not pretend to be exhaustive, as event-specific evaluation will always be necessary. The selected events types are: heat waves, cold spells, droughts, heavy precipitation events, and wind events leading to storm surges. These generally have a daily to seasonal time scale. They were selected because the underlying weather variables have long observational records.

In Section 2, we briefly describe the simulations. A more detailed description is given in a separate article (Ciavarella et al., 2017, in preparation). We also describe the data sets used. Section 3 is devoted to an overall assessment of the main biases in mean state, variability and extremes, as well as a comparison between simulated and observed trends. In Section 4, an extreme value analysis is carried out in order to investigate distribution tails. Section 5 is dedicated to an analysis of a few key processes 
124 conclusions for attribution are given.

\section{2. Simulations and observations}

\section{2.1 The HadGEM3-A simulations}

127 The simulations used in this work were generated by the Hadley Centre event attribution system

128 (Christidis et al., 2013a) that has facilitated numerous studies of different types of high-impact extreme

129 events. A typical attribution study involves pairs of large ensemble experiments with and without

130 anthropogenic forcings, from which the changing likelihood of extreme events under climate change

131 can be determined (Stott et al., 2016). The Hadley Centre system is built on the HadGEM3-A model

132 that was recently upgraded within the EUropean CLimate Event Interpretation and Attribution

133 (EUCLEIA) project (http://eucleia.eu/) and now features one of the highest resolution global models used in global event attribution research. The model runs at N216 horizontal resolution, equivalent to about $60 \mathrm{~km}$ at mid-latitudes, and comprises 85 vertical levels. The upgraded model also benefits from a new atmospheric science package with an improved dynamical core, which leads to better numerical stability (Williams et al., 2015).

An ensemble of 15 atmospheric simulations of the historical climate during the period 1960-2013 was produced with the new model and is the basis of the evaluation assessments discussed in this paper. A second ensemble of model runs without the effect of anthropogenic forcings was also generated and employed in attribution analyses (Christidis et al., 2016; Burke et al., 2016; Wilcox et al., 2017), but is not used here. The historical forcings in the model simulations include anthropogenic greenhouse gas, aerosols, tropospheric and stratospheric ozone emissions, changing land use, as well as natural changes in the solar output and volcanic aerosols (Jones et al., 2011). Ensemble members are generated by implementing random parameter perturbations as well as a stochastic kinetic energy backscatter scheme that accounts for energy sources on sub-grid scales (Christidis et al., 2013a). Monthly 
Surface Temperature (HadISST) v1 dataset (Rayner et al., 2003) provide boundary conditions for the simulations of the historical climate. Building on the multi-decadal simulations, an operational attribution system is currently being developed by firstly extending the model runs and increasing the ensemble size and then by continuing to extend the simulations on a seasonal timescale in a similar fashion to seasonal forecasting systems.

\subsection{Observations}

In this paper we use a number of observational data sets for the model simulations evaluation. In general, the NCEP/NCAR $20^{\text {th }}$ Century reanalysis 20CR re-analyses of sea level pressure have been used for characterizing atmospheric circulations. Surface temperatures and precipitation are either taken from CRUTS3.2 or from E-OBS data sets. Specific data sets have been used to study the landatmosphere interactions, described in Table 1.

\section{Model climatology, trends and variability}

\subsection{Mean states and trends}

In this section we review the main statistics of the model climate and compare it to observations. The mean state, time evolution, and interannual variability of metrics of mean and daily extremes in the 15-member HadGEM3-A N216 ensemble are compared to a variety of observational datasets (primarily CRUTS3.23 and E-OBS) for the June to August (JJA) and December to February (DJF) seasonal means. Spatial patterns have been considered over the European domain, and time series have been considered over three regions: Europe $\left(35-70^{\circ} \mathrm{N}, 10^{\circ} \mathrm{W}-40^{\circ} \mathrm{E}\right)$; Northern Europe $\left(50-60^{\circ} \mathrm{N}, 10^{\circ} \mathrm{W}-\right.$ $\left.25^{\circ} \mathrm{E}\right)$; and Southern Europe $\left(35-45^{\circ} \mathrm{N}, 10^{\circ} \mathrm{W}-25^{\circ} \mathrm{E}\right)$. Where regional means are considered, they only include model grid cells with a land fraction over $75 \%$, as observations are only available over land.

In general, HadGEM3-A represents the spatial pattern of mean near-surface temperature well, but does not reproduce the regional pattern of the trends. In summer, the model underestimates warming in southern Europe (in line with coupled models, van Oldenborgh et al, 2009; Kirtman and Power, 2013, 
173 discrepancies are not due to atmospheric internal long-term variability as they are found in most members (Figure 1f). However, when averaging over Europe, the model trend of $0.36 \pm 0.05 \mathrm{~K} /$ decade is compatible with the linear trends from CRUTS3.24 (0.33 $\pm 0.08 /$ decade), E-OBS v14.0 (0.35 $\pm 0.08 \mathrm{~K} /$ decade), and CRUTEM4.5 $(0.32 \pm 0.08 /$ decade). In the above numbers, the $95 \%$ confidence interval is provided. The histogram of the rank of the observations in the ensemble also shows an overall reliability of simulated temperatures at the continental scale (Figure 1i, see van Oldenborgh et al., 2013 for the reliability rank histograms calculations). When averaged over Northern Europe, the model slightly overestimates the positive trend in near-surface temperature $(0.36 \pm 0.05 \mathrm{~K} / \mathrm{decade}$ compared to $0.28-0.31 \mathrm{~K} /$ decade in observations), and underestimates the positive trend when averaged over Southern Europe (0.36 $\pm 0.06 \mathrm{~K} /$ decade compared to $0.41-0.44 \mathrm{~K} /$ decade in observations). Similar findings are obtained for the trends in daily minimal and maximal temperatures $\left(T_{\min }\right.$ and $\left.T_{\max }\right)$, yearly maximum of daily maxima and minima ( $T X x$ and $T N x$ ) (not shown). Least squares linear trends, as calculated above, were taken for the period 1960-2013, and should be interpreted with a degree of caution, due to the nonlinear nature of the time series evolution (see also Figure 3).

HadGEM3-A also represents the spatial pattern of mean summer precipitation, and trend patterns match the observed dipole, with some discrepancies (Figure 1c-d,g-h), and a general underestimation of precipitation trend in the ensemble members (Figure 1h). Positive precipitation trends over Scandinavia and negative trends over France and Eastern Europe are found. However, the model fails to capture the observed increase in precipitation over the UK and drying over Spain, and does not simulate drying over the full longitudinal extent of the Alps, as is seen in observations. The imbalance toward systematic trend underestimation is also shown in the rank histograms when considering the whole continent (Fig. 1j). The simulated trend over southern Europe is $-0.023 \pm 0.021 \mathrm{~mm} /$ day $/$ decade, while it is -0.042 and $-0.034 \mathrm{~mm} /$ day/decade in EOBS v14 and CRUTS3.23 respectively. In Northern Europe, trends are found in observations ( 0.052 and $0.046 \mathrm{~mm} /$ day/decade) however they are not significant. HadGEM3-A also shows no significant trend here (see also van Haren et al., 2013). 
In the winter season (Figure 2), mean states are again well simulated, but regional trend patterns are not well reproduced either. Over Scandinavia, the pattern of the near-surface temperature mean state is also well-represented by the model, but the model is too cold (Figure 2a-b). Observed temperature trends show significant warming over most of Europe at the $5 \%$ or $10 \%$ level, with the greatest warming over Scandinavia and the Baltics, but HadGEM3-A generally underestimates the magnitude and significance of the trends (Fig. 2e-f). However these trends discrepancies can be due to long-term atmospheric variability, as seen from Fig. $2 \mathrm{f}$ and the rank histogram of Figure $2 \mathrm{i}$, and no major incompatibility with the observation is found. HadGEM3-A simulates the pattern of the mean states and interannual variability in $T_{\min }, T_{\max }, T N x$, and $T X x$ well, but it does not reproduce the observed trends (not shown).

The pattern of the wintertime precipitation mean state is strongly tied to orography in both the model and observations. However, the model overestimates precipitation over the Pyrenees, Massif Central, Alps, and Greece, and underestimates it over the UK and Ireland (Figure 2c-d). Observed trends in precipitation have a strong dipole pattern, with drying in southern Europe, and increasing precipitation in the north resembling trends associated with a tendency towards positive NAO (see Deser et al., 2016). There is a hint of this pattern in the ensemble mean model trend, but the magnitude is much weaker than observed (Figure 3), and the ensemble fails to capture the main contrasts (Figure $2 \mathrm{~h}$ and 2j). Patterns in the mean state and interannual variability in extreme precipitation values are well represented in HadGEM3-A. Trends in these quantities are noisy in both the model output and observations (not shown).

\subsection{Variability}

In general the interannual variability is reasonably well simulated, as seen in Figure 3 from time series of individual members and superimposed observations. The model overestimates variability in seasonal mean daily mean and maximal temperatures (Figure 3), for European average, but simulates 
the variability in daily minimal temperatures fairly well (not shown). The overestimation in daily maxima is more marked in Northern Europe than in Southern Europe.

In winter, HadGEM3-A reproduces the inter-annual standard deviation of near-surface temperature over Europe as a whole, but shows a larger standard deviation in Southern Europe (Figure 3), and appears to underestimate it in Northern Europe. Interannual variability in $T_{\max }$ and $T_{\min }$ is well represented by HadGEM3-A in Europe, despite underestimates in the north, as for near-surface temperature. In southern Europe, the model overestimates variability in $T_{\max }$ (not shown), but underestimates it in $\mathrm{T}_{\min }$ (Fig. 3). Variability in TNx and TXx is underestimated in all regions (not shown; see also Section 4). Variability in seasonal precipitation amount, as well as in heavy precipitations (over $10 \mathrm{~mm}$ or $20 \mathrm{~mm}$ per day) is well represented by HadGEM3-A in general in both seasons (not shown). However, it should be kept in mind that the model resolution does not allow a proper representation of convective precipitation events.

\subsection{In summary}

HadGEM3-A generally shows reasonable performance in reproducing the observed mean-state, variability, and trends in daily means and extremes when considering Europe as a whole. However observed regional patterns of trends are not always well reproduced. For instance, the model fails to reproduce the observed JJA and DJF drying in southern Europe. In JJA, the model also locates the maximum in near-surface temperature trends too far east, so that the amplitude of warming over southern Europe is underestimated. In winter, temperature variability is high making trends from simulations and observations almost compatible despite a general tendency for the model to underestimate warming. The model ensemble fails to reproduce positive trends in temperature extremes $\left(T_{\min }, T_{\max }, T N x\right.$, and $\left.T X x\right)$ throughout Europe, and also underestimates interannual variability in TNx and TXX in winter. The amplitude of the dipole in precipitation trends in DJF is substantially underestimated by HadGEM3-A in DJF, and to a lesser extent in JJA. 

model's climatological biases in this season. For temperature this means a realistic mean response to external forcing and a potential for attributing temperature-related events. The differences in regional patterns of trends are partly due to the relatively short length of observational data sets combined with a chaotic atmosphere and weak SST dependence. It is also probably due to uncertainties in underlying processes (see Section 5). In winter the too weak warming trend may potentially lead to underestimation of likelihood reduction in winter cold spells. However, this discrepancy may also result from the large interannual and variability in winter temperatures. Some of the 15 members do show trends as observed in daily mean winter temperatures.

\section{Extreme value analysis}

A specific focus is given now on extremes of temperature and precipitation. The evaluation of the model's representation of extremes was undertaken using extreme value analysis, based on annual maxima of the historical runs in precipitation (rx1day) and maximum (TXX) and minimum daily temperature (TNn) discussed above. These were fitted to a stationary generalized extreme value (GEV) distribution (Coles, 2001). The three parameters of the GEV distribution, namely the location parameter $\mu$ (representing the mean values), scale parameter $\sigma$ (representing the typical range of values) and shape parameter $\xi$ (describing whether the distribution is heavy tailed or not), were evaluated alongside distributions fitted to the same extremes from E-OBS. Non-parametric bootstrapping (1000 replications) was used to estimate the uncertainty margins. Comparisons are made using the 0.5 - regular grid E-OBS product, which represents the resolution closest to that of the model.

For extreme maximum daily temperature (TXX), the location parameter is significantly under-estimated in Northern Europe and over-estimated in much of Southern and Eastern Europe. As illustrated in Figure 4, the model exhibits warm biases in hot events across Central, Eastern and, to a lesser extent, 
somewhat across most of the continent, but underestimated in Britain, and the shape parameter is overestimated somewhat over most of Northern Europe, indicating too heavy tail potentially related to unrealistically high drying in summer in this model (see Section 5).

For extreme minimum daily temperature (TNn), regions of complex topography (including the Alps and the western coastline of Scandinavia) are characterized by a clear under-estimation of the location parameter. The cold bias to the south of the Alps is also apparent in the analysis of cold events in Figure 4, with similar spatial features evident in multiple ensemble members. The scale parameter is reasonably well represented, but the shape parameter is much too large in Eastern Europe, where the model simulates too extreme very cold events. By contrast, the shape parameter is too small in much of Western Europe.

For extreme precipitation the broad coastal and topographical precipitation features are wellreproduced by the model, but both the location and scale parameters are consistently larger than those of observed extremes (Figure 5): the model generates too much rain in extremes with too much variability. This is particularly the case in Mediterranean coastal regions and immediately south of the Alps. This is the opposite of what one would intuitively expect: given the model's coarse resolution, extremes in the simulated precipitation field should typically be smaller in magnitude than those events occupying the same point of likelihood in the observed distribution.

\section{Process analysis}

The ability of a model to simulate physical and dynamical processes leading to extremes is key for its capacity to simulate their changes under human activities influence. Extreme events generally result from an ensemble of processes involving atmospheric dynamics, large-scale drivers, as well as regional to local-scale processes which interact with one another. Here, we evaluate whether the model captures the most important processes leading to extreme events. For the five types of events under study (heat and cold waves, heavy precipitation events, drought and storm surges) we examine in 
particular the role of large-scale circulation and a few key regional-to-local scale processes, such as

297 interaction with land surface.

In general, extreme weather events occur under specific types of weather patterns: heat waves, droughts and cold spells relate to long persisting anticyclones sitting over a large area. In Europe, heavy precipitation is associated either with summer convective episodes coming after a long warm period with the arrival of frontal systems with cold air aloft destabilizing the troposphere, or in long-lasting wintertime cyclonic episodes bringing in recurring storms. In each case typical atmospheric circulation patterns are found. Then, extreme events also result from amplifying processes, which may dominate in some cases, such as land-atmosphere interactions in particular in the case of heat waves and droughts (Seneviratne et al. 2010), and also cold spells through the effect of snow cover (Orsolini et al. 2013). Stratosphere-troposphere interactions have also been shown to be important in the build-up of cold spells (Baldwin and Dunkerton, 1999). Here we evaluate these processes in HadGEM3-A simulations.

\subsection{Atmospheric weather patterns}

One way to evaluate whether the model correctly simulates the atmospheric circulation variability is through the analysis of weather regimes. Weather regimes are usually defined as large typical clusters of atmospheric flows that are observed. The concept of weather regimes is based on dynamical systems theory analysis of atmospheric variability: certain phase-space areas may include slow-down of trajectories, due to the vicinity of stationary solutions (Legras and Ghil, 1985), or quasi-stationary solutions (Vautard and Legras 1988). Since then, a number of studies (e.g. Michelangeli et al., 1995; Cassou et al. 2005) have characterized weather regimes using cluster analysis. Over the North-East Atlantic and Europe, such an analysis usually finds four stable clusters from observations or reanalysis of sea-level pressure or geopotential height. 
Here, we compare clusters obtained by a $k$-means algorithm applied to the NCEP/NCAR reanalysis and the HadGEM3-A simulations carried out over the same period (1960-2013). The same North-Atlantic domain is used both for model and observations $\left[-80^{\circ} \mathrm{W}-50^{\circ} \mathrm{E}, 22.5^{\circ} \mathrm{N}-70^{\circ} \mathrm{N}\right]$. A separate analysis is done for winter (DJF) and summer (JJA) seasons using sea-level pressure fields.

The centroids of the obtained clusters for the NCEP/NCAR reanalysis and the HadGEM3-A model 15 member ensemble, are shown for winter in Figure 6a-h and for summer in figure 6i-p. The HadGEM3A model weather regimes centroids are quite similar to the observed ones with slight shifts. For instance, the "blocking" (BLO) regime is well represented in winter and summer but the "Atlantic ridge" (AR) regime has differences that can be seen mainly in winter. However, this should not be a major issue for European extremes of temperature and rain as this latter regime is generally not associated with extremes. Cold spells are usually characterized in winter by either the negative North Atlantic oscillation (NAO-) regime, as was the case for the winter of 2009-2010 (Cattiaux et al., 2010), or by the BLO regime. Mild winters with persistent rainfalls over Western Europe are characterized by the "Zonal flow" (ZO) regime as shown by Schaller et al. (2016).

Another important aspect for extremes is the frequency of occurrence of regimes. One expects that to correctly simulate the statistics of extreme events, a model must simulate correct frequencies in the weather regimes. In order to compare similar clusters statistics, we used the NCEP/NCAR cluster centroids SLP anomalies as reference and counted the number of SLP fields for which each centroid is nearest, both for NCEP/NCAR and HadGEM3-A fields for a best comparison. HadGEM3-A weather regime frequencies are well represented with respect to ones in NCEP/NCAR. BLO and NAO- regimes are well represented in both seasons while ZO (winter) and AL (summer) have slight differences to NCEP/NCAR (lower and higher frequencies of occurrence respectively).

Table 2 shows the frequencies of nearest neighbors calculated in this way. It is quite remarkable how well the frequencies match between observations and the model. We conclude that the HadGEM3-A 
model simulates quite well the main weather patterns of the North East Atlantic with mean frequencies that reproduce faithfully the observations.

\subsection{Atmospheric circulations associated with hot and cold events}

The previous analysis was made for weather patterns independently of extreme events. We now turn to the evaluation of the capability of HadGEM3-A in representing the specific weather patterns associated with hot and cold events in Central Europe (defined here as the average over $2^{\circ}-15^{\circ} \mathrm{E}$ and $47^{\circ} \mathrm{N}-54^{\circ} \mathrm{N}$ ). This analysis builds on Krueger et al. (2015) and is based on a composite analysis of temperatures and circulation states (characterized by the geopotential heights at $500 \mathrm{hPa}$ ) for hot and cold events. We show here results for hot extremes and cold events are shown in the supplement. The temperature data was deseasonalized (using a 10-day filter for calculating the climatology); prior to detecting hot and cold extremes the linear long-term trends over the analysis period were removed from each gridpoint.

Hot and cold events with a time scale of five days were obtained as consecutive values above the $95^{\text {th }}$ and below the $5^{\text {th }}$ daily temperature percentile for summer (JJA) and winter (DJF), respectively. These moderate extremes should occur under broadly similar circulation conditions to stronger extremes, but are well sampled (Krueger et al., 2015) and have been found useful (Alexander, 2016). Composites of all such events were calculated for the 1960-2013 period which yields 143 heat waves and 137 cold spells from the 20CR v2c in comparison to a range of $149-154$ hot spells and $147-150$ cold spells for the model ensemble, respectively (note that the reanalysis shows slightly, but significantly, fewer hot and cold spells). The associated circulation patterns are calculated as the composites of the $500 \mathrm{hhPa}$ geopotential height found for each occurrence of a cold- or hot temperature event, following Krueger et al. (2015). In contrast to Krueger et al. (2015), the composite analysis was performed for land-only temperatures. The analysis for the model was performed for each of the 15 ensemble members separately, with resulting composites then averaged to provide an ensemble mean value. 

though these are aggregated over events occurring over 54 years in each case. Larger differences between the ensemble members are found for summer. For the circulation associated with extreme hot events, there is high variability across the ensemble members while for the ensemble mean the geopotential pattern resembles a classic omega blocking in 20CR with the eastern, negative center of the blocking suppressed or moved in the average circulation of HadGEM3-A. The location of low pressure anomalies and their magnitude varies across ensemble members for this 54 year average. The spatial extent and intensity of heat waves varies across ensemble members consistent with the subtle variations in circulation (for example, compare middle of the second to bottom left panel for figures 7 and 8). The observations lie within that large variability.

Results for cold events are similar (Supplementary Figure 1 and 2), with a strong pressure gradient between a high and low in NW and SE Europe, respectively, causing cold spells, whose average intensity and extent varies depending on the tilt of the pressure gradient, again exemplifying the important role of atmospheric variability even on the long timescales averaged across here.

\subsection{Land-atmosphere interactions}

Land-atmosphere interactions are major processes in the development of many extremes and must therefore be well represented in view of attribution studies. This is particularly important for heat waves, which are expected to become more frequent with greenhouse gases increase (Seneviratne et al. 2012), with potential severe impacts on society and economy (Rosenzweig et al. 2001, Corti et al. 2009, Blauhut et al. 2015, Zhao et al., 2016). The uncertainty of projections of future temperatures and associated hot extremes is especially large in regions where a shift of the evapotranspiration regime is expected, i.e. where evapotranspiration is radiation-limited in today's climate but will become soilmoisture-limited in future climate. This is due to a large uncertainty in the representation of the land- 

addressed by validating and evaluating the involved modelled processes in present climate conditions against observations. Thanks to recent advances in the development of reference datasets for land key variables such as soil moisture (Orth and Seneviratne 2015) and evapotranspiration (Mueller et al. 2013), a comprehensive evaluation of the modelled land-atmosphere coupling became feasible.

401

We assess and evaluate the land-atmosphere coupling in the HadGEM3-A model in Europe by considering all parts of the overall coupling separately (see Figure 9 of Seneviratne et al. 2010). In particular we focus on (i) the coupling between soil moisture and evapotranspiration, (ii) the coupling between evapotranspiration and temperature (extremes), and (iii) the (resulting) coupling between precipitation and temperature (extremes). In terms of temperature we will focus on monthly mean temperature, and to represent hot extremes we use TXX.

The relationship between the variables involved in each part modelled by HadGEM3-A is compared with the corresponding observed interplay using state-of-the-art reference datasets of the corresponding variables (Table 1). Here we focus on the time period 1960-2013, however, due to limited availability of the reference datasets, the evaluation of evapotranspiration-related couplings is constrained to 1989-2005, and the evaluation of soil moisture-related couplings is restricted to 19842013. Note furthermore the different spatial resolutions between the employed reference datasets (see Table 1), and of the HadGEM3-A output data. Model output has been masked whenever the reference data was not available to ensure the same spatial and temporal basis of the analyses.

In order to focus on the highest coupling strengths, we perform all computations with monthly data using only the hottest month of each year. In the case of soil moisture and precipitation we use the previous month to capture their influence on subsequent temperature or evapotranspiration. For the estimation of the considered coupling strengths we consider 3 European subregions, (i) Northern Europe (NEU), (ii) Central Europe (CEU), and (iii) the Mediterranean (MED) as defined in Seneviratne et al. (2012). For the Mediterranean region, however, we focus on latitudes between $35^{\circ} \mathrm{N}-45^{\circ} \mathrm{N}$ instead 
of $30^{\circ} \mathrm{N}-45^{\circ} \mathrm{N}$ as in Seneviratne et al (2012) due to limited spatial availability of the reference datasets (region hence denoted as MED*). Coupling strengths are expressed as monthly correlations. Furthermore, we compare modelled versus reference distributions of the considered variables in the considered months.

Soil moisture - Evapotranspiration Coupling: The HadGEM3-A coupling between preceding soil moisture and evapotranspiration in the hottest month is compared with reference data in Figure 9. Apart from the apparent bias in evapotranspiration in NEU and CEU, HadGEM3-A captures the observed coupling well. Overall strength and the spatial pattern of the correlation between soil moisture and evapotranspiration are also well represented. With few exceptions the HadGEM3-A ensemble captures the observed coupling strength in all European regions. Only over the Iberian Peninsula (underestimation) and in Ireland (no coupling) the model results do not agree with the correlations across the reference datasets. Note the large spread of correlations between the individual ensemble members suggesting strong variability of the modelled coupling.

Evapotranspiration - Temperature Coupling: The HadGEM3-A coupling between evapotranspiration and temperature in the hottest month is compared with reference data in Figures 10 and 11 . While the overall strength and the north-south gradient in the correlation are represented in the model, its simulated spatial coupling pattern agrees only partially with the reference datasets. The transition zone with zero coupling strength between the positive coupling in NEU and the negative coupling in MED* is too wide in the model, and it is shifted northward as compared to the reference datasets. This contributes to the overestimation of hot temperature extremes by the HadGEM3-A model found in Section 4. The underestimation of the evapotranspiration-temperature coupling between $50^{\circ} \mathrm{N}-65 \mathrm{~N}^{\circ}$ also explains why the observed correlation is not contained in the HadGEM3-A ensemble in large parts of this region. This occurs even though the spread of correlations between the ensemble members of HadGEM3-A is large, as for the previous coupling (Figure 9 of Seneviratne et al., 2010). Results also show a Northward extension of coupling region, potentially creating too warm hot periods, in 
agreement with the extreme value analysis of Section 4. We find comparable results for mean and

447 extreme temperatures indicating almost no change of this coupling in heat waves.

448 We find a large spread of coupling strengths between the ensemble member simulations (not shown)

449 indicating large variability of the coupling. It remains unclear if this is a model-specific feature. This

450 could be tested by comparing the temporal variability of the coupling strength in the reference data

451 and in the model output using temporal subsets of the available data. However, this is beyond the

452 scope of this article. We note, however, that this variability could help to explain the offset in the spatial

453 patterns of coupling strengths between the reference datasets and the model.

Spring preconditioning of heat waves: We next investigate to what extent spring preconditioning of soil matters for individual heat wave metrics (see e.g. Vautard et al., 2007; Hirschi et al., 2011). A metric of European heat waves that targets impacts is used, based on maximum and minimum temperatures exceeding the $90^{\text {th }}$ percentile threshold for at least 3 days and 2 nights (Pezza et al., 2012; Cowan et al. 2017). This approach should be considered analogous to approaches using Excess Heat Factor (e.g. Perkins et al., 2012) or hottest daily maximum temperature of the year (Hauser et al., 2016) and hence relates to the index considered above. We tested the sensitivity of summer heat waves to preceeding wet and dry springs for different European sub-regions in E-OBS v14.0, and whether the HadGEM3-A can capture this sensitivity. Heat wave composites were calculated over summers following the top $20 \%$ driest and wettest springs (i.e. for E-OBS this is equivalent to the 14 driest and 14 wettest springs, for HadGEM3-A this corresponds to the 11 driest and 11 wettest springs per ensemble member) based on 3-month Standardized Precipitation Index (SPI; McKee et al., 1993) for spring ending in May, averaged over each region of interest (bounded regions in Figure 12). A non-parametric two-sample Wilcoxon sign-ranked test (Hollander and Wolfe, 1999) us used in order to determine if the summer 
Figure 12 shows the composite patterns following the wet and dry springs for the heat wave duration

471 (HWD), which describes the longest seasonal heat wave. The model composites are based on 11 springs each from the 15 historical ensemble members (165 springs in total). The patterns from E-OBS show that dry springs across southern Europe are systemically followed by longer summer heat waves compared to wet springs (Figure 12, left panels), with many Mediterranean regions exceeding 5.5 days on average. This is consistent with the results for coupling strength shown above (Figure 10). Further north into central and eastern continental Europe, this observed tendency becomes much weaker and less significant. Across southern England and northern France, despite the lack of significance there is a small increase in HWD following dry springs compared to wet springs. For western Scandinavia, longer summer heat waves tend to emerge following wetter springs, consistent with a positive evapotranspiration temperature coupling, which suggests that antecedent soil moisture conditions, based on the SPI, are not a significant predictor of summer-time heat wave activity.

In general, HadGEM3-A shows a smaller effect of dry springs on HWDs across the western Mediterranean, however, it captures the significant differences compared to the wet spring composites (Figure 12; right panels). The model also appears to overestimate the dry-spring HWDs over the far eastern Mediterranean including Romania. Further north, the model simulates a much weaker spring SPI - summer HWD relationship, with strong positive biases over most of Scandinavia (compared to Esignificant control over heat wave activity (also seen in the simulated heat wave amplitude; not shown); this signal is more pronounced in the model if upper layer soil moisture? is used instead of the SPI (not shown). Despite model biases, the patterns across southern Europe imply that dry springs and winters do exert a strong influence on summer heat wave activity, confirming earlier observational studies 492 (Quesada et al., 2012, Vautard et al., 2007) and consistent with results for coupling strength shown 493 above (Figure 10). For central Europe, Scandinavia and the Baltic states, there is only a weak association to spring conditions in both model and observations, although the model captures the strong spring 
coupling region as found above (Figure 10), and as such, the model appears to have a stronger response

to dry spring anomalies in Eastern Europe compared with observations. The results for both E-OBS and

HadGEM3-A are affected by sampling uncertainty, particularly for observations, and the fact that the

SPI is averaged over large domains with many different climates; thus care must be taken in interpreting

the spring-summer coupling. Furthermore, the SPI may not fully represent variations in the simulated

upper soil moisture over northern latitudes (e.g. Scandinavia), given low correlations ( 0.1) in the

model, compared to 0.93 over western Mediterranean.

503

504

505

506

507

508

509

510

511

512

513

514

515

516

517

\subsection{Stratosphere-troposphere interactions}

A key process in cold spells development is the interaction between stratosphere and troposphere, which must also be well represented in view of cold spell events attribution. In the extra-tropical NH winter there is a tendency for anomalies to propagate from the stratosphere to the troposphere where they disturb the NAO and the weather related to this dominating mode of variability. In particular, weak stratospheric vortex events are followed by an increased probability of cold temperatures and cold extremes in Europe. Although this coupling between the stratosphere and the troposphere on intraseasonal time-scales has been known for more than a decade (Baldwin and Dunkerton, 1999; Christiansen, 2001) there still remain unanswered questions about how to represent the stratospheric variability in order to optimally catch the coupling. Here, we evaluate the HadGEM3-A model's ability to reproduce the observed connection between the stratosphere and the troposphere.

The downward propagation from the stratosphere to the troposphere can be demonstrated by lagged correlations between zonal mean wind at $60^{\circ} \mathrm{N}, 10 \mathrm{hPa}$ (a measure of the stratospheric vortex) and the zonal mean wind at other vertical levels at $60^{\circ} \mathrm{N}$.

Unfortunately, only monthly averaged stratospheric model data have been saved in the model experiments while daily should be used. To partly overcome this we have interpolated the monthly averages to daily values. To evaluate the soundness of this approach we compare them with observations sub-sampled to monthly values and then interpolated back to daily values. In daily 
observations the downward propagation is clearly seen with maximum correlations at the surface lagging those in the stratosphere with about 2 weeks. In the model there is a similar connection between the stratosphere and the troposphere but it appears less lagged. This is at least partly due to the smoothing effect of dealing with monthly data (as seen in the top left panel of Fig. 13).

The fact that the stratosphere is leading the troposphere also in the model is more clearly seen in Fig. 13 which shows the correlations between the stratospheric vortex (zonal mean wind at $60^{\circ} \mathrm{N} 10 \mathrm{hPa}$ ) and the NAO. The effect of a weak NAO on European temperatures are well known (Hurrel et al., 2003), thus Figure $14 \mathrm{~d}$ shows the model skill to simulate a key connection between stratosphere and the circulation pattern present during cold spells occurrences.

Finally, Figure 14 shows the correlation between the anomaly of the stratospheric vortex, defined as above, and surface temperatures, for observations and five model ensemble members. For the observations we find a pattern that is consistent with the impact of the NAO: positive correlations in the middle and Northern Europe and negative correlations in Southern Europe (although these correlations are not statistically significant). For the model we find that the ensemble members agree on the general pattern, as revealed by ensemble mean correlations although there are considerable differences between ensemble members.

\subsection{Processes involved in storm surges}

Storm surges can occur in numerous places in Europe and driving processes are essentially the interaction between winds, low pressure systems, seas dynamics, and waves. It would be a tremendous task, well beyond the scope of this article, to assess the model's capacity to simulate weather conditions conducive to storm surges everywhere in Europe. Only a case study is developed here as an example, in the Baltic sea, a region that is known for witnessing severe surges due to the geometry of the sea and weather conditions. These occur in particular when strong winds develop after the passage of cyclones over the Baltic Sea, potentially inducing extreme variations in sea level resulting in storm 
surges e.g. along the German Coast in the southwestern Baltic Sea region (Sztobryn et al., 2005; Hünicke et al., 2015). During strong onshore winds, the sea level rises due to wind set-up.

In this section we assess the ability of using HadGEM3-A as atmospheric forcing data to drive the regional ocean model TRIM-NP (Kapitza, 2008) for calculating water level of the Baltic Sea in $12.8 \mathrm{~km}$ spatial resolution. Results are summarized here as a parallel study assesses the attribution of these events to climate change (Klehmet et al., 2017, in preparation). Dynamical downscaling of HadGEM3A data has been done with 7 ensemble members only (due to computing costs) for 1971-2010. To obtain a gridded reference data for the evaluation, one model reconstruction of water level of TRIMNP has been performed using the CoastDat2 data (Geyer, 2014) as atmospheric forcing. CoastDat2 is a regional atmospheric hindcast simulation for the European continent for 1948 to 2012 obtained with the regional climate model COSMO-CLM (Rockel et al., 2008) using the global reanalysis data of NCEPR1 (Kalnay et al., 1996; Kistler et al., 2001) as forcing data. We then first directly compare the outputs of HadGEM3A-TRIM-data with those of CoastDat-TRIM.

Maximal November water level anomalies for selected grid boxes representing locations co-located to cities along the German coast (here : Warnemünde, Travemünde) for 1971-2010 relative to the 19712010 mean of the HadGEM3A-TRIM-data underestimate extreme water levels as compared with CoastDat-TRIM (Figure 15). The high water levels of both storm surge events in 1995 and 2006 shown by CoastDat-TRIM, used as reference data, are not found in the time series of historical HadGEM3ATRIM ensemble simulations that represent actual climate with anthropogenic forcing.

However, extreme winds in the area are properly reproduced by the model. We compared the simulated distribution of three simple wind indicators with ERA-Interim surface winds: the wind speed itself, the wind speed conditional on winds in the North-East Quadrant, and the North-Easterly component of the daily wind field calculated as $N E W=-U-V, U$ and $V$ being respectively the zonal and meridional wind components. All indices were averaged over the area $\left(10^{\circ} \mathrm{E}-18^{\circ} \mathrm{E} ; 54^{\circ} \mathrm{N}-56^{\circ} \mathrm{N}\right)$, which encompasses the South-Western Baltic Sea. Distributions are fairly well represented as shown in Figure 
573 underestimation is quite homogeneous irrespective of the wind speed, and reaches about $6 \%$ in the

574 extreme values, but cannot explain the too low water levels of storm surges in Figure 15. However,

575 ERA-Interim winds may themselves have biases and one should be prudent in the interpretation of

576 these results. Comparisons with winds over sea remains difficult as observation data are largely

577 missing. Therefore, at least for this Baltic Sea, we could not find any major HadGEM3-A simulation bias

578 hindering the attribution of storm surges.

579

580

581

582

583

584

\section{Conclusion and discussion}

In view of attribution of change of likelihood of extreme events to human activity, we have presented a number of comparisons between an ensemble of 15 atmospheric simulations from the HadGEM3-A model and various observations over Europe. We have presented an analysis of model mean and extreme statistics, and an assessment of its capacity to simulate key processes involved in a few extreme events development. Results presented here show that HadGEM3-A simulates the atmospheric mean, variability and extremes in Europe fairly realistically. As for any climate model, some biases are found but (i) the major regional patterns of the climatology of the main variables is well simulated and (ii) dynamical weather patterns are faithfully simulated by the model. This provides confidence in use for attribution. Concerning extreme values, too strong heat extremes and heavy precipitation are found, but the parameters of distributions do not exhibit qualitatively different behavior than in observations. However, simulations do not well capture the observed patterns and amplitudes of trends in temperature and precipitation, which is partly due to a trend in circulation that is different from the observed one and from other climate models. While for temperature our trend analysis shows that these discrepancies can be due to internal atmospheric variability (especially in winter), precipitation trends have slight, but systematic, biases across the ensemble, which remain unexplained. 
598 variability of circulation types is well simulated, both in terms of spatial patterns and occurrence

599 frequencies. Physical processes behind these statistics consistently demonstrate the ability of the model to simulate extreme events. Here are the main consequences that could be drawn for each of the five types of extremes that we considered in this study.

\section{Heat Waves}

Simulated weather patterns associated with hot events compare favorably with those shown in the reanalysis, however, with significant internal variability in the representation of events between model ensemble members. However, heat build-up is also amplified by land-atmosphere feedbacks. We found that HadGEM3-A captures land-atmosphere interactions in present-day climate reasonably well. We assessed the different parts of this coupling and find that especially the soil moistureevapotranspiration coupling is well represented, while the evapotranspiration-temperature coupling is underestimated in regions between $50^{\circ} \mathrm{N}-65 \mathrm{~N}^{\circ}$. The overall coupling is investigated by correlating preceding precipitation with temperature in the hottest month where the correlations of the model output and between the reference datasets are similar, but the spatial patterns are not entirely captured. Consistently, observed heat wave metrics following wet springs are significantly different from those following dry springs, particularly in Southern Europe and this process is reasonably well captured in the model.

615 Too strong drying is taking place in the model with exaggerated evapotranspiration, in central and northern Europe in the hottest month, a probable reason for too many and strong heat waves. Simulated summer temperatures actually exhibit a too large interannual variability in these regions. Whether all these phenomena are linked remains to be confirmed with further analyses, however, our results are suggestive of a bias towards a too fast transition towards a soil-moisture limited regime in 
preconditioning on heat wave metrics appears reasonably simulated, although findings are consistent with the biases discussed above.

The consequences for attribution of these results remain difficult to evaluate. The overestimated interannual variability, together with evapotranspiration overestimation in large parts of Europe suggests that heat waves responses to atmospheric composition changes may be too large. However, observed trends in summer temperatures themselves do not show evidence of such oversensitivity. This indicates that biases may not have a major influence on the skill of the model to simulate the overall change in odds of heat waves or that some of the model errors compensate for current climate.

\section{Droughts}

Droughts have not been investigated in detail. However, several remarks can be made. The above results for temperatures and evapotranspiration should in principle translate in the model simulating too strong summer droughts. In addition, interannual precipitation variability appears to be slightly overestimated in summer, potentially leading to both drier and wetter summers. However a deeper investigation is required to better understand biases of the model and whether these biases are hindering attribution of drought in Europe. It should be noted that climate models have large differences in trends in droughts in Central Europe.

\section{Cold spells}

The circulation associated with cold events in Central Europe is well captured by the model and individual model ensemble members again show long-term variations in the extent and intensity of average cold spells linked to atmospheric internal variability. Extreme value analysis of extreme cold winter temperatures show a fairly good agreement between simulated and observed values. However, the simulations are not free of biases in the frequency of cold spells. Weather regimes such as blocking or negative NAO, which usually drive cold spells in Europe, are well simulated, although their trend does not necessary match that in the model. Interactions and lagged correlations between the stratospheric vortex and tropospheric NAO and European temperatures are similar in model and 
observations. Therefore, we did not find any major process hindering the representation of cold spells. However, the trends in circulation and temperature are not well-simulated. Due to high natural variability it cannot be assessed how this translates to trends in cold extremes.

\section{Extreme precipitation}

Extreme daily precipitation are in large parts of Europe due to convective phenomena and thus local by nature. Global climate models usually have difficulties in simulating such phenomena given their coarse spatial resolution. HadGEM3-A has a wet bias in these extremes, associated with a too-large variability, especially around the Mediterranean sea. In this area we expect daily precipitation patterns to have a smaller scale than the model resolution calling for prudence in attribution interpretation from this model. However, it is noteworthy that the spatial pattern of extreme precipitation distributions is quite similar to observed. Also, despite the biases, the simulations exhibit GEV parameters that are quite consistent with observations, which could make the simulations eligible for attribution of precipitation extremes once the bias has been corrected.

\section{Storm surges}

Results for storm surges indicate an underestimation of the events amplitude when a regional ocean model is driven by HadGEM3-A as compared to a regional atmospheric hindcast obtained by downscaling the NCEP-R1 reanalysis. Comparisons of simulated winds with ERA-Interim reanalysis show a good performance of the model for strong winds or strong North-Easterlies in the SouthWestern Baltic Sea region where storm surges occur in Northern Germany, indicating that winds in the investigated domain are actually not the main factor of underestimation. Thus HadGEM3-A model simulations can a priori be used for storm surge attribution.

\section{Acknowledgements}


673 (EUCLEIA) FP7 SPACE project, Grant Agreement $n^{\circ} 607085$, and concerned principally its Work Package

6746 (Evaluation and diagnostics). NC and AC, FL and PS were also supported by the Joint BEIS/Defra Met

Office Hadley Centre Climate Programme (GA01101).

\section{References}

Alexander L. (2016) Global observed long-term changes in temperature and precipitation extremes: A review of progress and limitations in IPCC assessments and beyond. Weather and Climate Extremes Volume 11, March 2016, Pages 4-16.

Angélil, O., Perkins-Kirkpatrick, S., Alexander, L. V., et al. Comparing regional precipitation and temperature extremes in climate model and reanalysis products. Weather and Climate Extremes, 2016, vol. 13, p. 35-43.

Attribution of Extreme Weather Events in the Context of Climate Change (National Academies, 2016). https://www.nap.edu/catalog/21852/attribution-of-extreme-weather-events-in-the-context-ofclimate-change

Baldwin, M. P., \& Dunkerton, T. J. (1999) Propagation of the Arctic Oscillation from the stratosphere to the troposphere. Journal of Geophysical Research: Atmospheres, 104(D24), 30937-30946.

Bellprat, O., Kotlarski, S., Lüthi, D., \& Schär, C. (2014) Physical constraints for temperature biases in climate models. Geophysical Research Letters, 40(15), 4042-4047.

Bellprat, O., and F. Doblas-Reyes, (2016) Attribution of extreme weather and climate events overestimated by unreliable climate simulations. Geophys. Res. Lett., doi: 10.1002/2015GL067189.

Bindoff NL, Stott PA, AchutaRao KM, Allen MR, Gillett N, Gutzler D, Hansingo K, Hegerl G, et al. (2013). Chapter 10 - Detection and attribution of climate change: From global to regional. In: Climate Change 2013: The Physical Science Basis. IPCC Working Group I Contribution to AR5. Cambridge: Cambridge University Press.

Blauhut, V., Gudmundsson L. \& Stahl, K. (2015) Towards pan-European drought risk maps: quantifying the link between drought indices and reported drought impacts. Environ. Res. Lett. 10, 014008.

Burke, C., P.A. Stott, Y. Sun, A. Ciavarella (2016) Wettest May in South-Eastern China for 40 years, In "Explaining Extremes of 2015 from a Climate Perspective", Bull. Amer. Meteor. Soc. Sup.

Cassou, C., Terray, L. \& Phillips, A. S. (2015) Tropical Atlantic influence on European heat waves. J. Clim. 18, 2805_2811.

Cattiaux, J., R. Vautard,, C. Cassou, P. Yiou, V. Masson-Delmotte and F. Codron (2010) Winter 2010 in Europe: a cold extreme in a warming climate. Geophys. Res. Lett., 37, L20704, doi:10.1029/2010GL044613.

Christiansen, B. (2001) Downward propagation of zonal mean zonal wind anomalies from the stratosphere to the troposphere: Model and reanalysis. Journal of Geophysical Research: Atmospheres, 106(D21), 27307-27322. 
Christidis, N., P.A. Stott, A. Scaife, A. Arribas, G.S. Jones, D. Copsey, J.R. Knight, W.J. Tennant (2013a) A new HadGEM3-A based system for attribution of weather and climate-related extreme events, J. Climate, 26, 2756-2783

Christidis, N., P.A. Stott, D.J. Karoly, A. Ciavarella (2013b) An attribution study of the heavy rainfall over eastern Australia in March 2012, In "Explaining Extremes of 2012 from a Climate Perspective", Bull. Amer. Meteor. Soc. Supp.

Christidis, N., P.A. Stott, A. Ciavarella (2014) The effect of anthropogenic climate change on the cold spring of 2013 in the UK. In "Explaining Extremes of 2013 from a Climate Perspective". Bull. Amer. Meteor. Soc., 95(9), S79-S82

Christidis, N., M. McCarthy, A. Ciavarella, P.A. Stott (2016) Human contribution to the record sunshine of 2014/15 in the United Kingdom, In "Explaining Extremes of 2015 from a Climate Perspective", Bull. Amer. Meteor. Soc., supp.

Coles, S., Bawa, J., Trenner, L., \& Dorazio, P. (2001) An introduction to statistical modeling of extreme values (Vol. 208). London: Springer.

Corti, T., Muccione, V., Köllner-Heck, P., Bresch, D. \& Seneviratne, S. I. (2009) Simulating past droughts and associated building damages in France. Hydrol. Earth Syst. Sci. 13, 1739-1747.

Cowan, T., A. Purich, S. Perkins, A. Pezza, G. Boschat, and K. Sadler (2014) More Frequent, Longer, and Hotter Heat Waves for Australia in the Twenty-First Century. Journal of Climate, 27, 5851-5871, doi: 10.1175/JCLI-D-14-00092.1.

Cowan, T., G. Hegerl, I. Colfescu, A. Purich and G. Boshcat (2017) Factors contributing to record-breaking heat waves over the Great Plains during the 1930s Dust Bowl, Journal of Climate, doi: $10.1175 / \mathrm{JCLI}-$ D-16-0436.1 (in press).

Deser, C., J. W. Hurrell and A. S. Phillips (2016) The Role of the North Atlantic Oscillation in European Climate Projections. Clim. Dyn., doi: 10.1007/s00382-016-3502-z

Eden, J.M., Bellprat, O., Kew, S., Lenderink, G., Manola, I., Omrani, H. and Oldenborgh, G.J. van. (2017) Extreme precipitation in the Netherlands: an event attribution case study, Clim. Dynam. (submitted).

Eden, J.M., Wolter, K., Otto, F.E.L. and Oldenborgh, G.J. van. (2016) Multi-method attribution analysis of extreme precipitation in Boulder, Colorado, Env. Res. Lett., 11, 124009. DOI:10.1088/17489326/11/12/124009.

Fischer, E. M., Rajczak, J., \& Schär, C. (2012) Changes in European summer temperature variability revisited. Geophysical Research Letters, 39(19).

Geyer, B. (2014) High-resolution atmospheric reconstruction for Europe 1948-2012: coastDat2, Earth Syst. Sci. Data, 6, 147-164

van Haren, R., van Oldenborgh, G. J., Lenderink, G., Collins, M., \& Hazeleger, W. (2013) SST and circulation trend biases cause an underestimation of European precipitation trends. Climate dynamics, 40(1-2), 1-20.

Hauser, M., R. Orth, and S. I. Seneviratne (2016) Role of soil moisture versus recent climate change for the 2010 heat wave in Russia, Geophysical Research Letters, 43, 2819-2826, doi:10.1002/2016GL068036. 
Hauser, M., L. Gudmundsson, R. Orth, A. Jézéquel, K. Haustein, R. Vautard, G. J. van Oldenborgh and S. I. Seneviratne, 2017. Methods and model dependency of extreme event attribution : the 2015 European drought. Earth's Future, submitted.

Haylock, M.R., N. Hofstra, A.M.G. Klein Tank, E.J. Klok, P.D. Jones, M. New. (2008) A European daily highresolution gridded dataset of surface temperature and precipitation. J. Geophys. Res. 113, D20119.

Hegerl, G., \& Zwiers, F. (2011) Use of models in detection and attribution of climate change. Wiley Interdisciplinary Reviews: Climate Change, 2(4), 570-591.

Hirschi, M., Seneviratne, S. I., Alexandrov, V., Boberg, F., Boroneant, C., Christensen, O. B., Formayer, H., Orlowsky, B., Stepanek, P. (2011) Observational evidence for soil-moisture impact on hot extremes in southeastern Europe. Nature Geoscience, 4(1), 17-21.

Hollander, M., and D. A. Wolfe (1999) Nonparametric Statistical Methods. John Wiley and Sons, 787 pp. Hünicke B., Zorita E. et al., 2015: The BACC II Author Team, Second Assessment of Climate Change for the Baltic Sea Basin, Regional Climate Studies, DOI 10.1007/978-3-319-16006-1_9.

Hurrell, J. W., Kushnir, Y., Ottersen, G., \& Visbeck, M. (2003) An overview of the North Atlantic oscillation (pp. 1-35). American Geophysical Union.

Jones, C.D., J.K. Hughes, N. Bellouin, S.C. Hardiman, G.S Jones, J. Knight, S. Liddicoat, F.M. O'Connor, R.J. Andres, C. Bell, K.-O. Boo, A. Bozzo, N. Butchart, P. Cadule, K.D. Corbin, M. Doutriaux-Boucher, P. Friedlingstein, J. Gornall, L.Gray, P.R. Halloran, G.Hurtt, W.J. Ingram, J.-F. Lamarque, R.M. Law, M. Meinshausen, S. Osprey, E.J. Palin, L. Parsons Chin, T. Raddatz, M.G. Sanderson, A.A. Sellar, A. Schurer, P. Valdes, N. Wood, S. Woodward, M. Yoshioka, M.Zerroukat (2011) The HadGEM2-ES implementation of CMIP5 centennial simulations, Geosci. Model Dev., 4, 543-570

Kalnay, E., Kanamitsu, M., Kistler, R., Collins, W., Deaven, D., Gandin, L., Iredell, M., Saha, S., White, G., Woollen, J., Zhu, Y., Chelliah, M., Ebisuzaki, W., Higgins, W., Janowiak, J., Mo, K. C., Ropelewski, C., Wang, J., Leetmaa, A., Reynolds, R., Jenne, R., and Joseph, D. (1996) The NCEP/NCAR 40-year reanalysis project, B. Am. Meteorol. Soc., 77, 437-471.

Kapitza, H. (2008) Mops -a morphodynamical prediction system on cluster computers. In: High performance computing for computational science - VECPAR 2008, J. M. Laginha, M. Palma, P.R. Amestoy, M. Dayde, M. Mattoso, J. Lopez (Eds.), pp. 63-68. Lecture Notes in Computer Science, Springer Verlag.

Kirtman, B., S.B. Power, J.A. Adedoyin, G.J. Boer, R. Bojariu, I. Camilloni, F.J. Doblas-Reyes, A.M. Fiore, M. Kimoto, G.A. Meehl, M. Prather, A. Sarr, C. Schär, R. Sutton, G.J. van Oldenborgh, G. Vecchi and H.J. Wang (2013) Near-term Climate Change: Projections and Predictability. In: Climate Change 2013: The Physical Science Basis. Contribution of Working Group I to the Fifth Assessment Report of the Intergovernmental Panel on Climate Change [Stocker, T.F., D. Qin, G.-K. Plattner, M. Tignor, S.K. Allen, J. Boschung, A. Nauels, Y. Xia, V. Bex and P.M. Midgley (eds.)]. Cambridge University Press, Cambridge, United Kingdom and New York, NY, USA, pp. 953-1028, doi:10.1017/CBO9781107415324.023.

Kistler, R., Kalnay, E., Collins,W., Saha, S., White, G.,Woollen, J., Chelliah, M., Ebisuzaki,W., Kanamitsu, M., Kousky, V., van den Dool, H., Jenne, R., and Fiorino, M. (2001) The NCEP-NCAR 50-year reanalysis: Monthly means CD-ROM and documentation, B. Am. Meteorol. Soc., 82, 247-267.

Krueger, O., Hegerl, G. C., \& Tett, S. F. (2015) Evaluation of mechanisms of hot and cold days in climate models over Central Europe. Environmental Research Letters, 10(1), 014002. 
Legras, B., and M. Ghil, (1985) Persistent anomalies, blocking and variations in atmospheric predictability, J. Atmos. Sci., 42, 433-471.

Lott, F., N. Christidis, P.A. Stott (2013) Can the 2011 East African drought be attributed to humaninduced climate change? Geophys. Res. Lett., 40, 1177-1181

Lott, F. C., \& Stott, P. A. (2016). Evaluating Simulated Fraction of Attributable Risk Using Climate Observations. Journal of Climate, 29(12), 4565-4575.

McKee, T. B., N. J. Doesken, and J. Kleist (1993) The relationship of drought frequency and duration to time scales. In Proceedings of the 8th Conference on Applied Climatology, American Meteorological Society, Boston, MA, Vol. 17, 179-183.

Michelangeli, P.A., Vautard, R., Legras, B., (1995) Weather regimes: recurrence and quasi-stationarity, J. Atmos. Sci., 52, 1237-1256.

Mueller, B., Hirschi, M., Jimenez, C., Ciais, P., Dirmeyer, P. A., Dolman, A. J., Fisher, J. B., Jung, M., Ludwig, F., Maignan, F., Miralles, D., McCabe, M. F., Reichstein, M., Sheffield, J., Wang, K. C., Wood, E. F., Y. Zhang, Y. \& Seneviratne, S. I. (2013) Benchmark products for land evapotranspiration: LandFlux-EVAL multi-dataset synthesis. Hydrol. Earth Syst. Sci. 17, 3707-3720.

van Oldenborgh, G. J., Drijfhout, S., Ulden, A. V., Haarsma, R., Sterl, A., Severijns, C., W. Hazeleger \& Dijkstra, H. (2009) Western Europe is warming much faster than expected. Climate of the Past, 5(1), 112.

van Oldenborgh, G. J., Reyes, F. D., Drijfhout, S. S., \& Hawkins, E. (2013). Reliability of regional climate model trends. Environmental Research Letters, 8(1), 014055.

Orsolini, Y. J., R. Senan, G. Balsamo, F. J. Doblas-Reyes, F. Vitart, A. Weisheimer, A. Carrasco, and R. E. Benestad, (2013) Impact of snow initialization on sub-seasonal forecasts. Clim. Dyn., 41, 1969-1982, doi:10.1007/s00382-013-1782-0.

Orth, R. \& Seneviratne, S. I. (2015) Introduction of a simple-model-based land surface dataset for Europe. Env. Res. Lett. 10, 044,012.

Pall, P., Aina, T., Stone, D. A., Stott, P. A., Nozawa, T., Hilberts, A. G. J., Lohmann, D., Allen, M. R. (2011) Anthropogenic greenhouse gas contribution to flood risk in England and Wales in autumn 2000. Nature, 470(7334), 382-385.

Perkins, S. E., L. V. Alexander, and J. R. Nairn (2012) Increasing frequency, intensity and duration of observed global heatwaves and warm spells. Geophysical Research Letters, 39, L20714, doi: 10.1029/2012GL053361.

Pezza, A. B., P. van Rensch, and W. Cai (2012) Severe heat waves in Southern Australia: synoptic climatology and large scale connections. Climate Dynamics, 38, 209-224, doi:10.1007/s00382-0111016-2.

Philip, S., S. F. Kew, G. J. van Oldenborgh, E. Aalbers, R. Vautard, F. Otto, K. Haustein, F. Habets, R. Singh and H. Cullen (2017) Validation of a rapid attribution of the May/June 2016 flood-inducing precipitation in France to climate change, Climate Dynamics, submitted.

Quesada, B., Vautard, R., Yiou, P., Hirschi, M. \& Seneviratne, S. I. (2012) Asymmetric European summer heat predictability from wet and dry southern winters and springs. Nature Clim. Change 2, 736-741. 

(2003) Global analyses of sea surface temperature, sea ice, and night marine air temperature since the late nineteenth century, J. Geophys. Res., 108, doi:10.1029/2002JD002670

Reichstein, M. et al. (2013) Climate extremes and the carbon cycle. Nature 500, 287-295.

840

Rockel, B., A. Will, und A. Hense (2008) The Regional Climate Model COSMO-CLM (CCLM), Editorial, Meteorol. Z., Volume 12, Number 4, 347-348.

Rosenzweig, C., Iglesias, A. \& Yang X (2001) Climate change and extreme weather events; implications for food production, plant diseases, and pests. Global Change \& Hum. Health 2, 90-104.

Schaller, N., A. L. Kay, R. Lamb, N. R. Massey, G.-J. van Oldenborgh, F. E. L. Otto, S. N. Sparrow, R. Vautard, P. Yiou, A. Bowery, S. M. Crooks, C. Huntingford, W. Ingram, R. Jones, T. Legg, J. Miller, J. Skeggs, D. Wallom, S. Wilson \& M. R. Allen (2015) Human influence on climate in the 2014 Southern England winter floods and their impacts. Nature climate change, doi:10.1038/nclimate2927.

Seneviratne, S.I., Corti, T., Davin, E. L., Hirschi, M., Jaeger, E. B., Lehner, I., Orlowsky, B. \&. Teuling, A. J., (2010) Investigating soil moisture-climate interactions in a changing climate: A review. Earth-Science Reviews, 99, 3-4, 125-161.

Seneviratne, S. I. et al. (2012) Managing the Risks of Extreme Events and Disasters to Advance Climate Change Adaptation 109-230 (Cambridge Univ. Press, 2012).

Seneviratne, S.I., Donat, M., Pitman, A. J., Knutti, R. \& Wilby, R. L. (2016) Allowable $\mathrm{CO}_{2}$ emissions based on regional and impact-related climate targets. Nature 529, 477-483.

Sippel, S., F. E. L. Otto, M. Forkel, M. R. Allen, B. P. Guillod, M. Heimann, M. Reichstein, S. I.

Seneviratne, K. Thonicke, and M. D. Mahecha (2016) A novel bias correction methodology for climate impact simulations, Earth Syst. Dyn., 7, 71-88, doi:10.5194/esd-7-71-2016.

Stegehuis, A., R. Vautard, P. Ciais, R Teuling, M. Jung, and P. Yiou, 2013: Summer temperatures in Europe and land heat fluxes in observation-based data and regional climate model simulations. Climate Dynamics, 41, 455-477.

Stott, P.A., N. Christidis, F. Otto, Y. Sun, J.-P. Vanderlinden, G.-J. van Oldenborgh, R. Vautard, H. von Storch, P. Walton, P. Yiou, F.W. Zwiers (2016) Attribution of extreme weather and climate-related events, WIREs Clim. Change, 7, 23-41.

Sztobryn M., Stigge H-J, Wiebliński D, Weidig B, Stanislawczyk, I, Kańska A, Krzysztofik B, Kowalska B, Letkiewicz B, Mykita M, (2005) Storm Surges in the Southern Baltic Sea (Western and Central Parts), Berichte des Bundesamtes für Seeschifffahrt und Hydrographie Nr. 39.

University of East Anglia Climatic Research Unit; Harris, I.C.; Jones, P.D. (2015) CRU TS3.23: Climatic Research Unit (CRU) Time-Series (TS) Version 3.23 of High Resolution Gridded Data of Month-by-month Variation in Climate (Jan. 1901- Dec. 2014). Centre for Environmental Data Analysis, 09 November 2015. doi:10.5285/4c7fdfa6-f176-4c58-acee-683d5e9d2ed5. h http://dx.doi.org/10.5285/4c7fdfa6-f1764c58-acee-683d5e9d2ed5

Vautard, R., and B. Legras (1988) On the source of midlatitude low-frequency variability. Part II: Nonlinear equilibration of weather regimes. J. Atmos. Sci., 45, 2845-2867.

Vautard, R., P. Yiou, F. D’Andrea, N. de Noblet, N. Viovy, C. Cassou, J. Polcher, P. Ciais, M. Kageyama, and Y. Fan (2007) Summertime European heat and drought waves induced by wintertime Mediterranean rainfall deficit, Geophys. Res. Lett., 34, L07711, doi:10.1029/2006GL028001 
877 Wilcox, L.J., P. Yiou, M. Hauser, F. C. Lott, G. J. van Oldenborgh, I. Colfescu, B. Dong, G. Hegerl, L. Shaffrey, 878 and R. Sutton (2017) Multiple perspectives on the attribution of the extreme European summer of 8792012 to climate change, Climate Dynamics, First Online, doi:10.1007/s00382-017-3822-7

880 Williams, K.D., C.M. Harris, A. Bodas-Salcedo, J. Camp, R.E. Comer, D. Copsey, D. Fereday, T. Graham, R. 881 Hill, T. Hinton, P. Hyder, S. Ineson, G. Masato, S.F. Milton, M.J. Roberts, D.P. Rowell, C. Sanchez, A. Shelly, 882 B. Sinha, D.N. Walters, A. West, T. Woollings, P.K. Xavier (2015) The Met Office Global Coupled model 8832.0 (GC2) configuration, Geosci. Model Dev., 8, 1509-1524.

884 Zhao Y., B. Sultan, R. Vautard, P. Braconnot, H.J. Wang and A. Ducharne (2016) Potential escalation of 885 heat-related working costs with climate and socio-economic changes in China. Proc. Nat. Acad. Sci., $886113,4640-4645$. 
887

888

889

890

891

892

893

894

895

896

897

898

899

900

901

902

903

904

905

906

907

908

909

910

911

\section{Figure Captions}

Figure 1: JJA mean near-surface temperature: (a) mean state (1960-2013) from CRUTS3.23; (b) mean state (1960-2013) from HadGEM3-A; (e) linear trends (1960-2013) from CRUTS3.23; (f) the number of HadGEM3-A ensemble members simulating a trend smaller than observed; (i) rank histogram over all land grid points counting the probability of the observations falling in each bin between the ranked simulated values. (c), (d), (g), (h), (j) are the equivalent plots for precipitation. Hatching in panels (e) and $(\mathrm{g})$ indicates where trends are significant at the $10 \%$ level $(p<0.1)$; cross-hatching indicates significance at the $5 \%$ level $(p<0.05)$.

Figure 2: Same as Figure 1 but for the winter season (DJF).

Figure 3: Left, middle and right panels: Evolution of seasonal mean daily mean temperatures in Europe, Southern Europe and Northern Europe; First row: JJA daily mean temperatures; Second row: JJA daily max temperatures; Third row: DJF daily mean temperatures; Fourth row: daily min temperatures.

Figure 4: Three left columns: parameters of the GEV distribution fitted to observations (left panels) and the model simulations (center panels for the distribution of annual maxima in daily temperature (TXx). $\mu$ refers to the location parameter which is related to the mean value, $\sigma$ the scale parameter, related to the range, and $\zeta$ the shape parameter, diagnosing if the distribution is heavy-tailed (large value of $\zeta$ ). The differences between the parameters of the observed and simulated GEV fits are shown in the right column of panels. For $\mu$ and $\xi$ the difference is expressed in absolute terms; $\sigma$ the difference is expressed as a ratio. Stippling indicates areas where the observed-simulated difference is larger than the $95 \%$ confidence intervals. Three right columns: same as left columns for the GEV distributions of the minimal temperatures Tnn.

Figure 5: As Figure 4 but for the distribution of annual maxima in daily precipitation. The fourth row of panel shows the ratio of the scale parameter $\sigma$ and location parameter $\mu$, with the difference again expressed as a ratio. 
Figure 6: Centroids of the four weather regimes sea-level pressure anomalies as obtained from the NCEP/NCAR re-analyses (a-d for winter, i-I for summer) and HadGEM3-A (Ensemble of 15 members, e$h$ for winter, $m-p$ for summer). First column: Atlantic Ridge (AR) regime, second column: Blocking (BLO) regime, third column: Negative NAO (NAO-) regime and fourth column: Zonal (ZO) regime for winter $(d, h)$ and Atlantic Low (AL) regime for summer (I, p).

Figure 7: JJA Composites of the standardized near-surface temperature for hot summer events over Central Europe in Had-GEM3-N216 historical forcing ensemble members 1-15 ( lines 1-3), ensemble mean (line 4, left) and and 20CR ensemble mean ( line 4, right). The composites have been derived from all cases where the area-averaged and 5-day averaged temperature over Central Europe is larger than its 95th seasonal percentile in JJA.

Figure 8: as figure 7, but showing composites of the standardized near-surface geopotential height at $500 \mathrm{mb}$ during hot summer events from Figure 7 over Central Europe.

Figure 9: Relationship between July evapotranspiration and June soil moisture averaged across European subregions (left panels), in observations (gray) and HadGEM3-A (black). The considered time period is 1989-2005.Correlation between July evapotranspiration and June soil moisture (right panels) in observations (top) and HadGEM3-A ensemble median (middle). Bottom plot indicates whether or not HadGEM3-A ensemble captures observed coupling strength. Considered time period is 1989-2005.

Figure 10: Relationship between temperature and evapotranspiration in July averaged across European subregions, in observations (gray) and HadGEM3-A ensemble median (black). The considered time period is 1989-2005. The range of correlations across HadGEM3-A ensemble members is shown in red if the observed correlation is not contained.

Figure 11: Correlation between temperature and evapotranspiration in July in observations (top) and HadGEM3-A ensemble median (middle). Bottom plot indicates whether or not HadGEM3-A ensemble captures observed coupling strength. Considered time period is 1989-2005. 
Figure 12: Composite of average duration (HWD) of the longest summer heat wave following the (top) $20 \%$ driest, and (bottom) 20\% wettest springs for (left) E-OBS (1950-2015) and for (right) fifteen HadGEM3-A historical members (1960-2013), based on Standardised Precipitation Index (SPI) averaged over each bounded region (i.e. each regions' HWD pattern is composited based on its own wet and dry spring ranking). Stippling indicates points that show a statistically significant difference at the $95 \%$ level between dry and wet spring composites, based on a two sample Wilcoxon signed-rank test (Hollander and Wolfe 1999). Significant differences are only marked on the dry-spring composite maps. HWD values for regions without heat waves are set to zero. Each composite consists of 14 and 165 springs for E-OBS and HadGEM3-A (i.e. 11 springs $\times 15$ ensemble members), respectively.

Figure 13: Correlations of winter zonal mean zonal wind anomalies at $60 \mathrm{~N}$ with that at $10 \mathrm{hPa}$ as function of pressure and time lag. Positive lags mean that the stratosphere leads. Light and dark shading identify regions where the correlations are significantly different from zero at the $5 \%$ and $1 \%$ levels as estimated with a Monte-Carlo method that takes serial correlations into account. Top left: NCEP daily. Top right: NCEP monthly. Bottom left: A typical member from HadGEM3-A ensemble. Bottom right: correlations between the stratospheric vortex (zonal mean wind at $60 \mathrm{~N}, 10 \mathrm{hPa}$ ) and the NAO as function of lag (positive lags mean that the stratosphere leads). Annual cycle has been removed. Winter (DJF). NCEP (green), a typical HadGEM-3A ensemble member (blue), NCEP interpolated from monthly values (green, dashed). The NAO is calculated as the leading principal component of sea-level pressure.

Figure 14: Correlations between the stratospheric vortex and surface temperatures. Annual cycle has been removed. Winter months (DJF). Large dots indicate correlations that have been estimated to be significantly different from zero ( $5 \%$ level) as estimated with a Monte-Carlo method that takes serial correlations into account. Upper left panel: Observations (E-Obs for surface temperature, NCEP for stratospheric vortex). Other panels: Different members from HadGEM-3A ensemble. 
960 Figure 15. November anomalies of maximum water level [m] for 1971-2010 based on reconstructed 961 model data (Coastdat-TRIM) and historical HadGEM3-A-TRIM (hist) ensemble members 1-7. Selected 962 grid boxes represent locations co-located with German cities of Travemünde (left) and Warnemünde 963 (right).

964 Figure 16: Quantile-quantile plots of the distributions of the three ERA-Interim vs. HadGEM3-A derived 965 indices of wind in the South-West Baltic sea (see main text for definitions of the indicators). All wind 966 values or wind speeds are expressed as $\mathrm{ms}^{-1}$. 


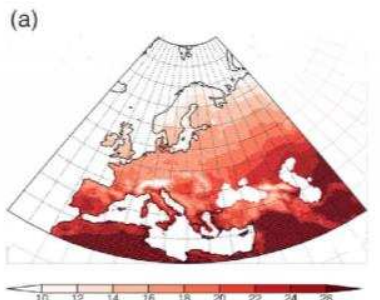

(e)

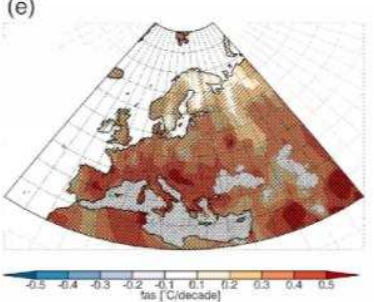

(b)

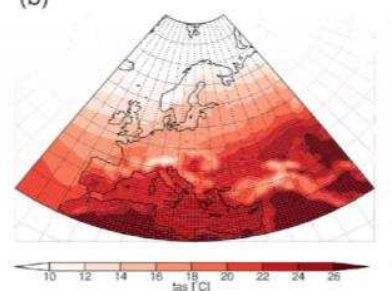

(f)
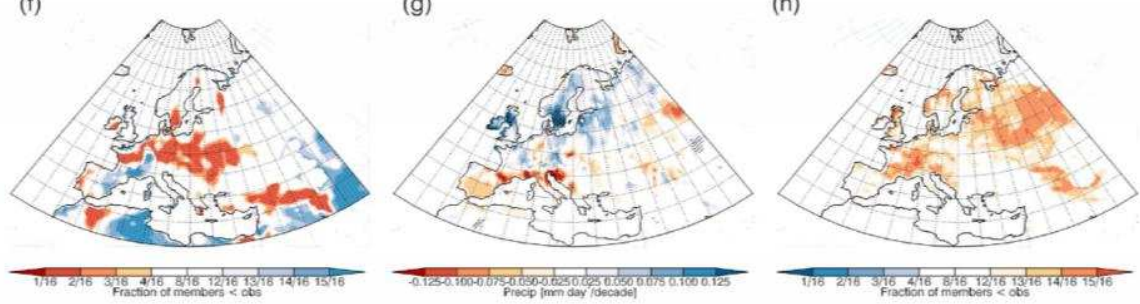

(c)

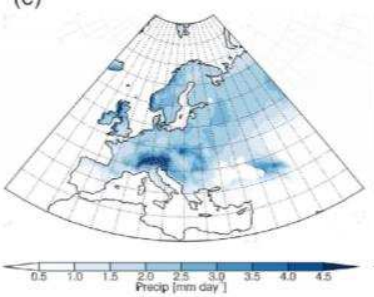

(g)

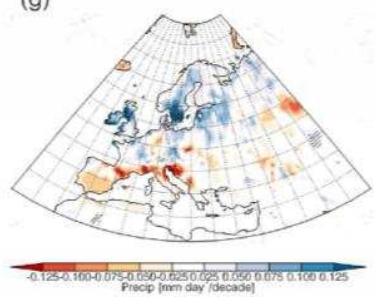

(h)

(d)

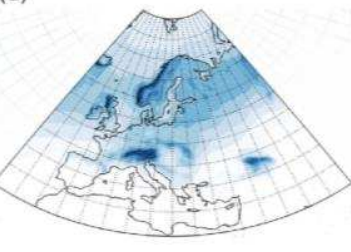

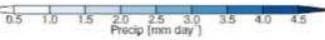

rank for HadGEM3-A rel. precip. trends vs CRU TS 1960-2009

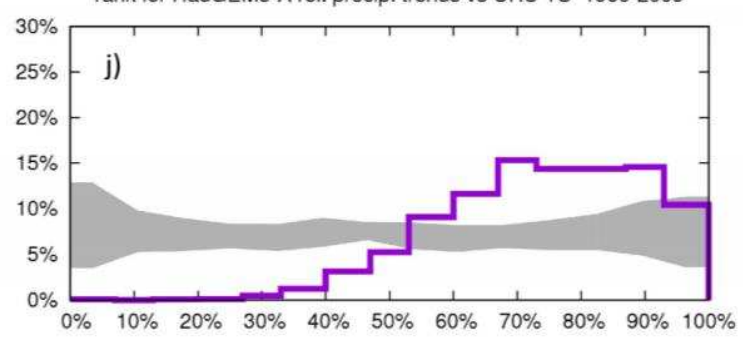

974

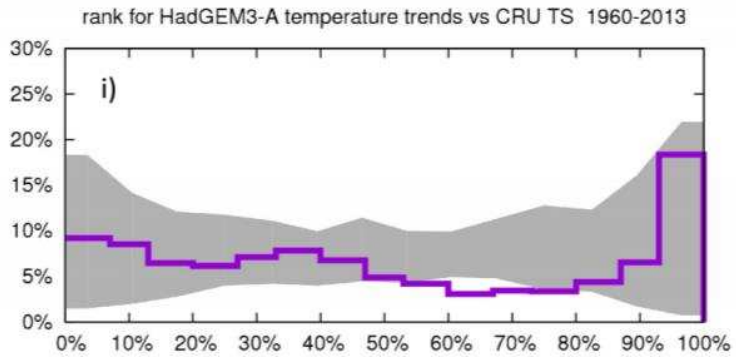

975

976

977

Figure 1

978 
(a)

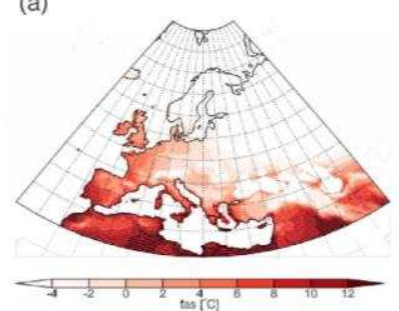

(e)

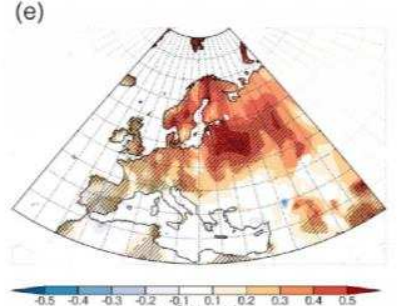

(b)

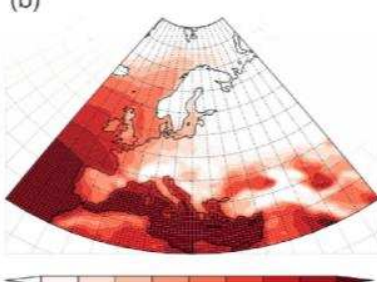

(f)

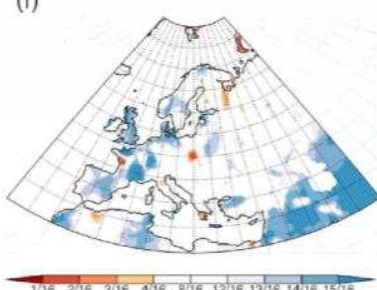

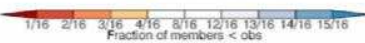

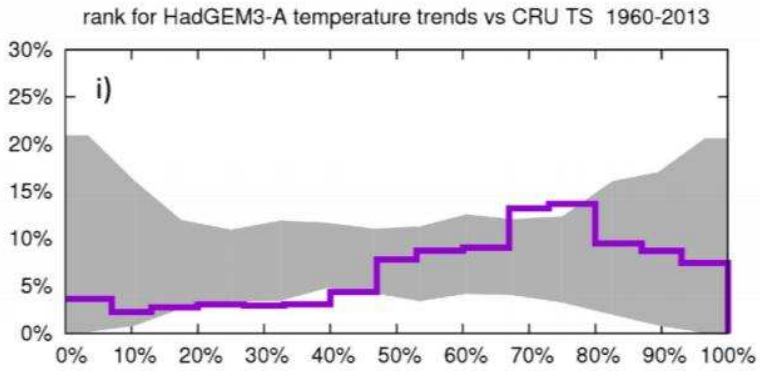

(c)

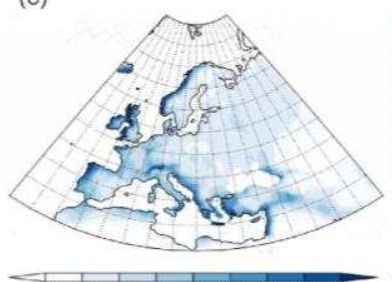

(g)

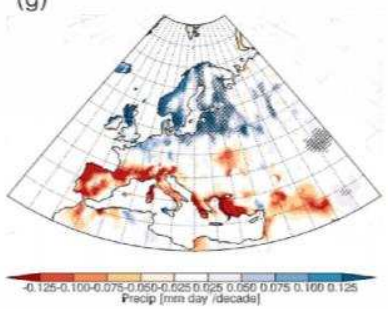

(d)

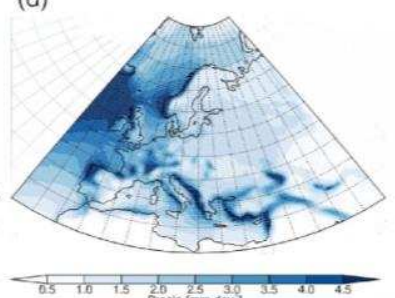

(h)

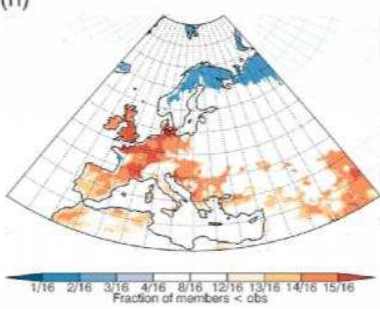

rank for HadGEM3-A rel. precip. trends vs CRU TS $1960-2009$

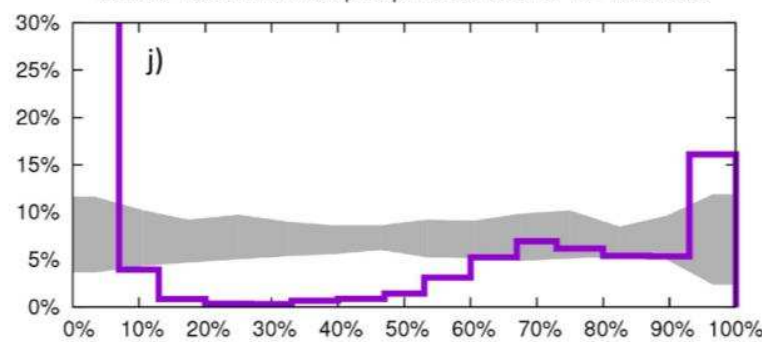

981

982

Figure 2 

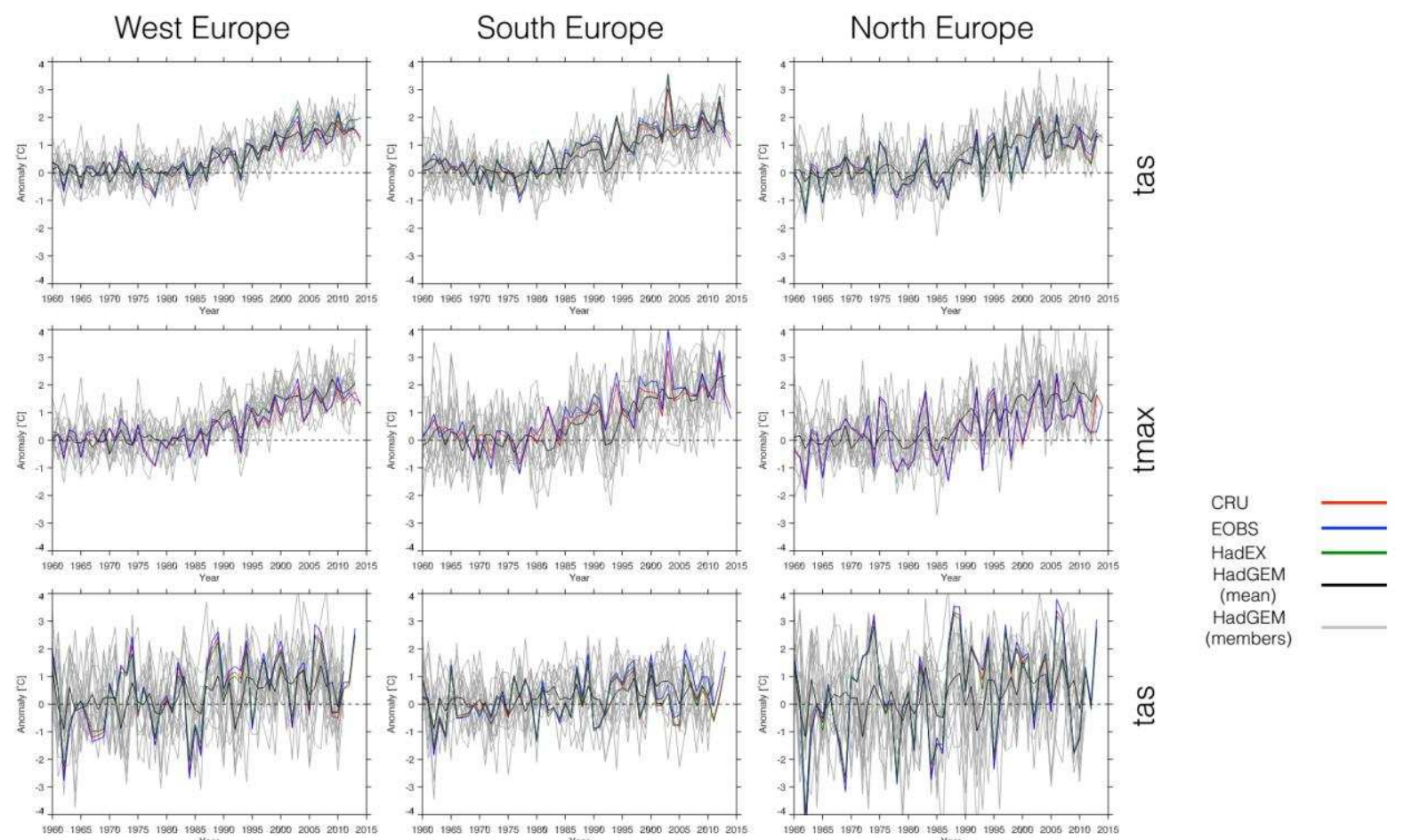

$\underset{\varpi}{\mathbb{1}}$
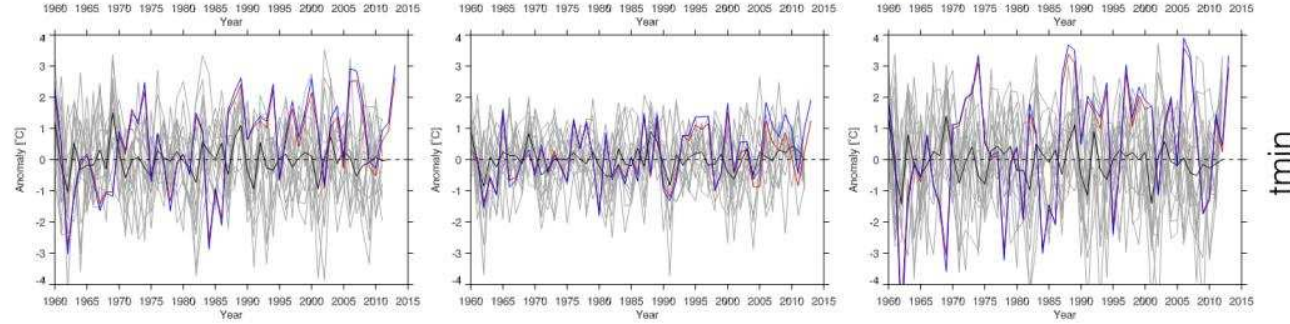

Figure3 

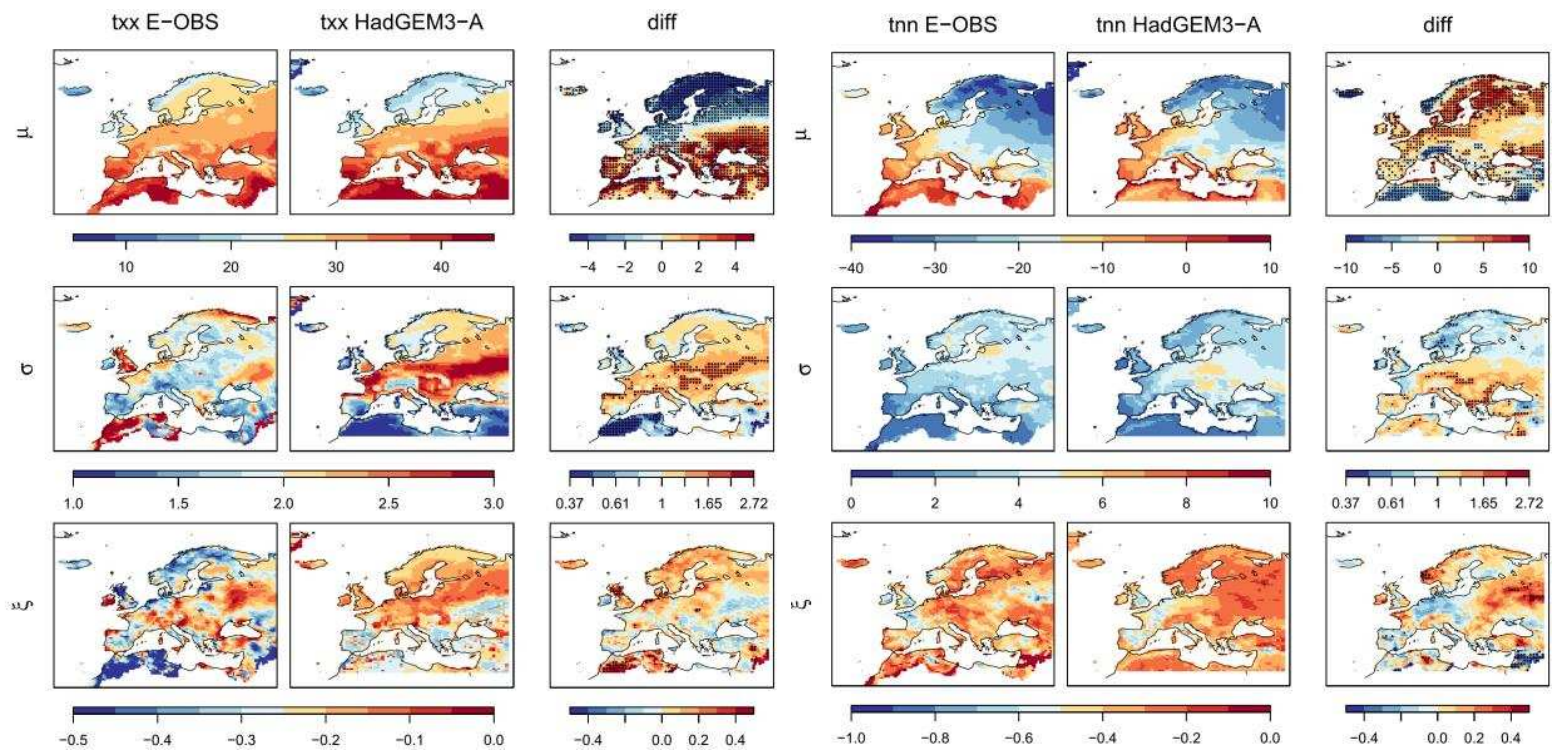

989

990

$991 \quad$ Figure 4

992 

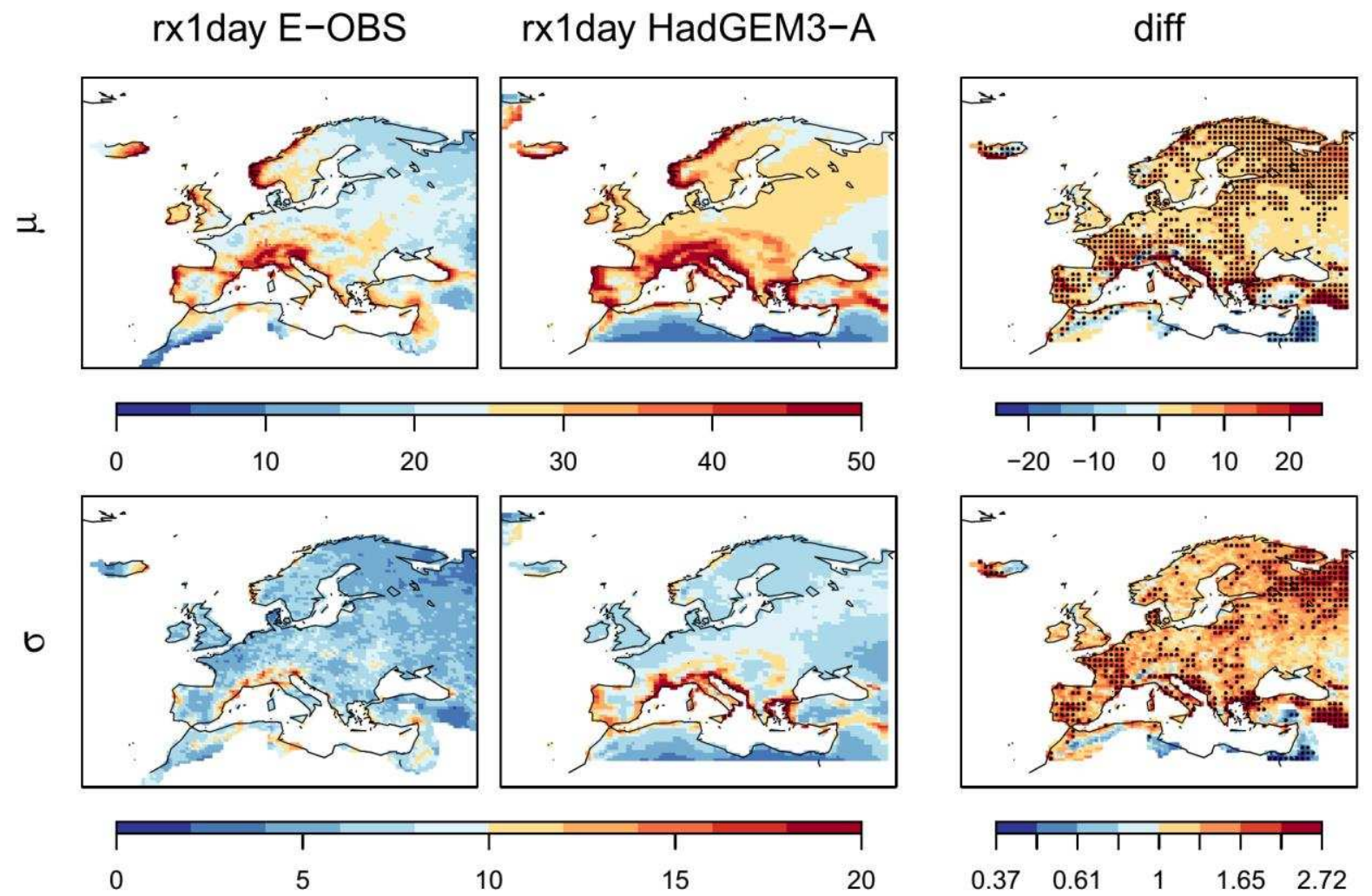

993
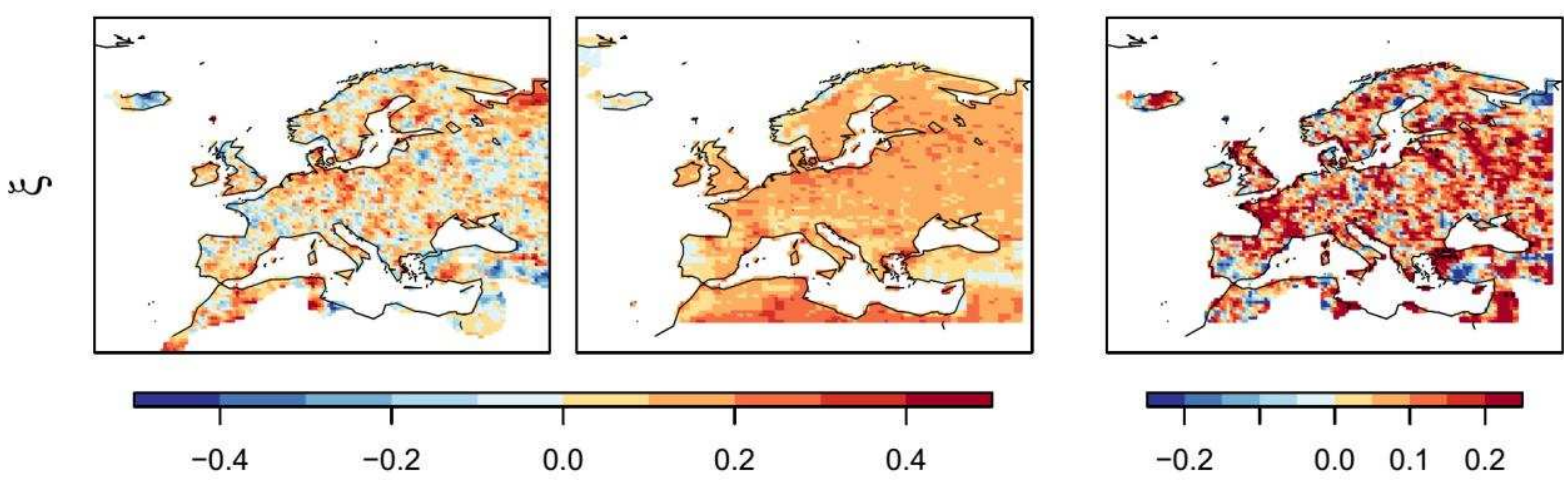

994 Figure 5 

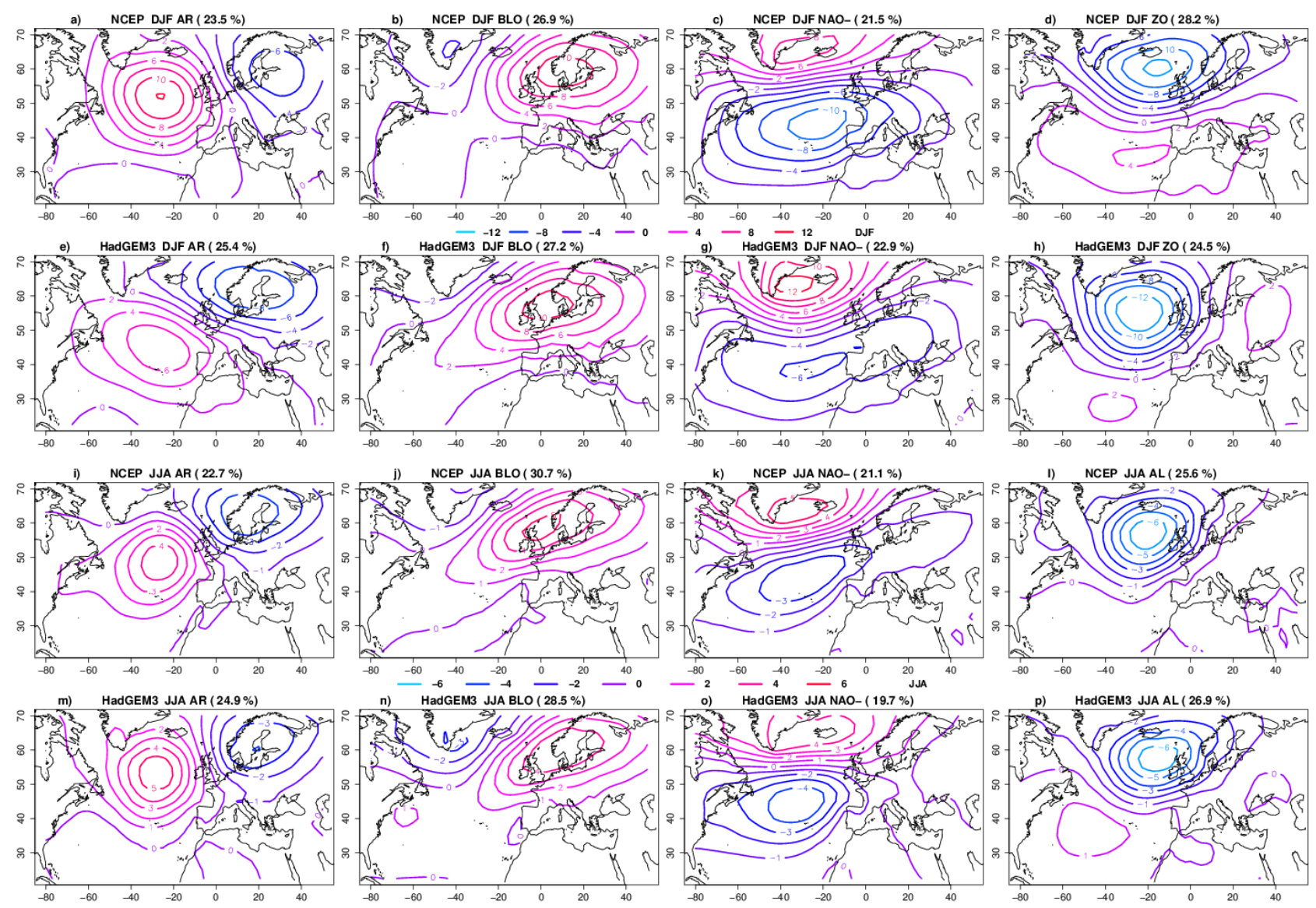

Figure 6 

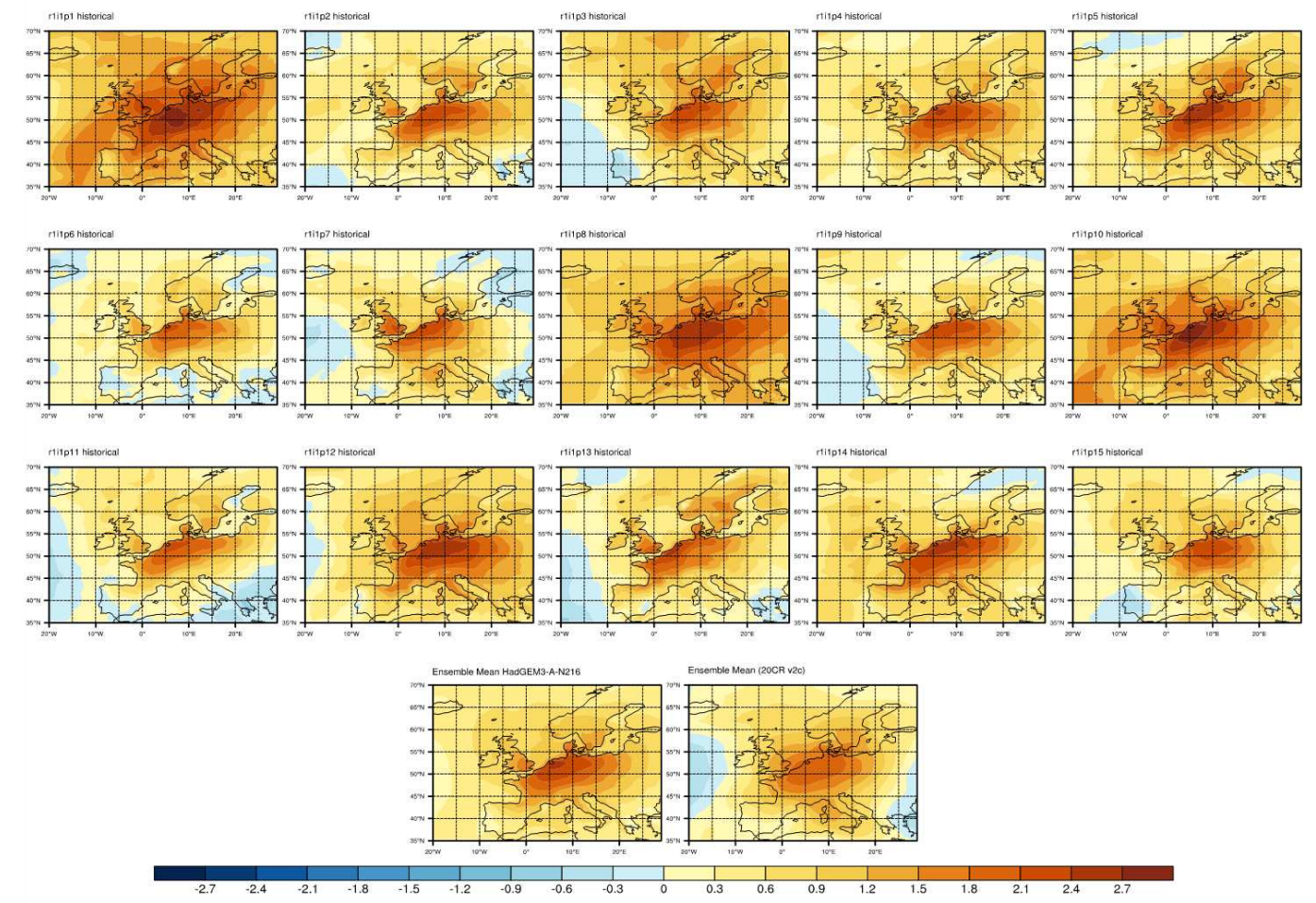

1001

1002 Figure 7

1003
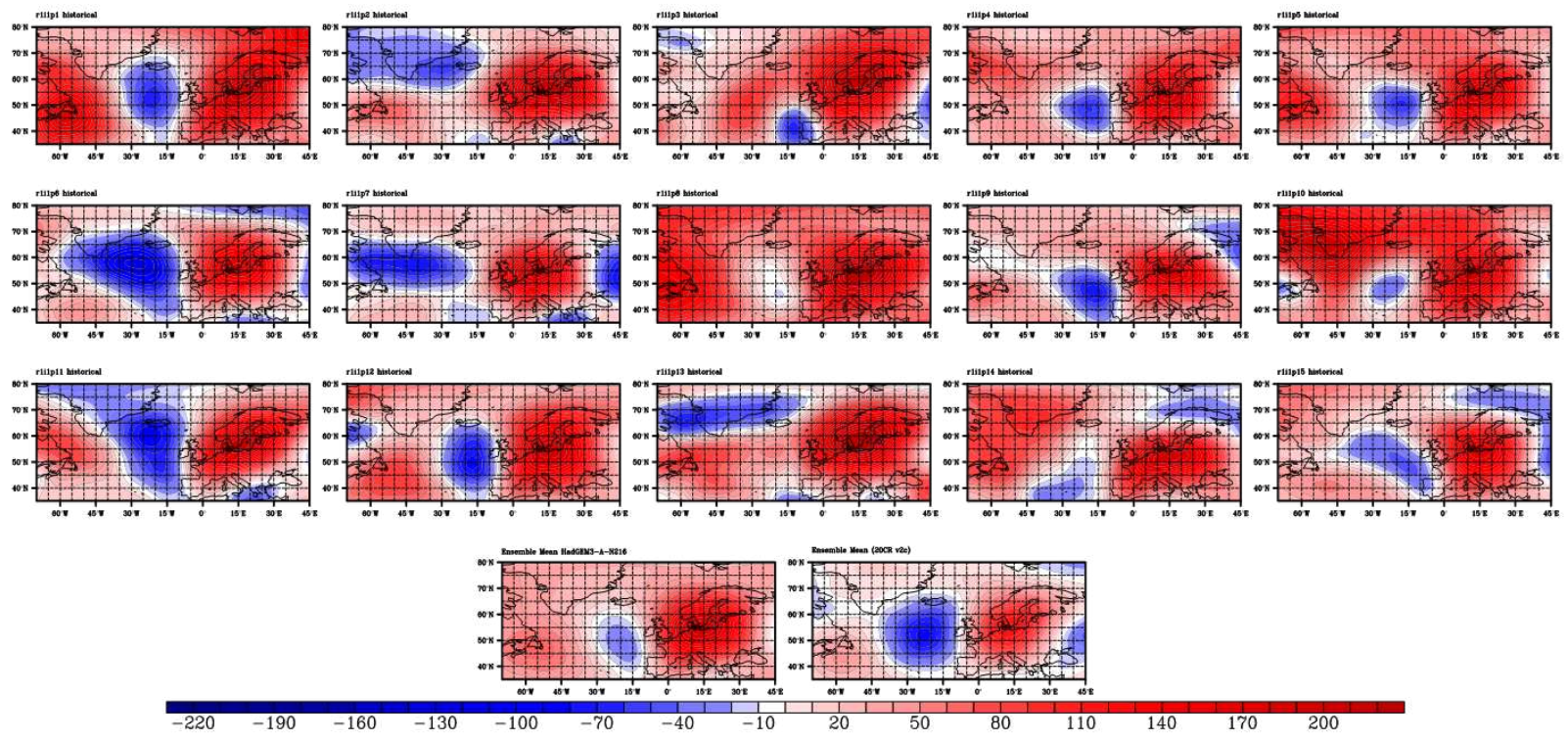

Figure 8 
ET in hottest month
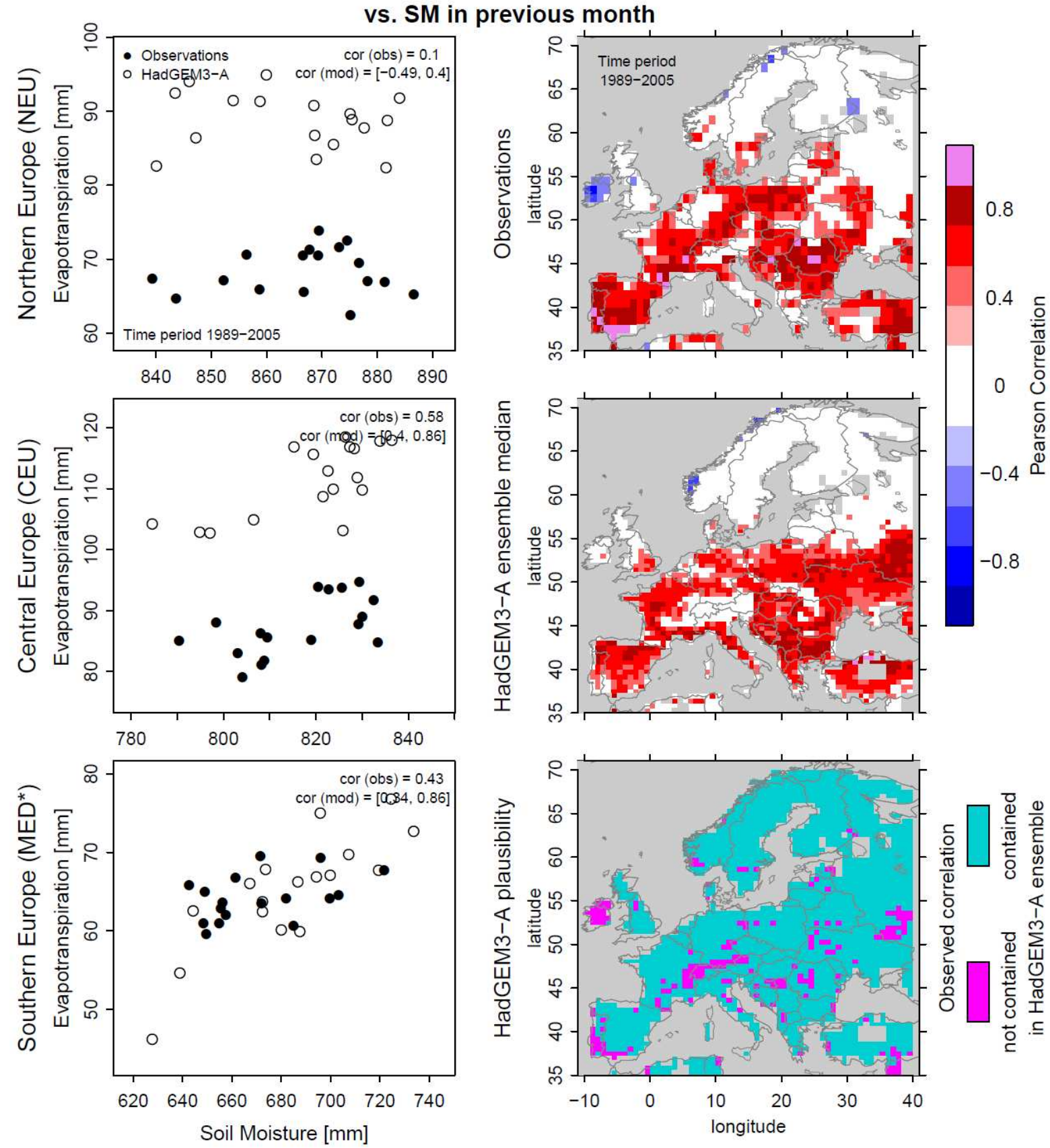

1008

1009

Figure 9

1010 
monthly mean T in hottest month TXX in hottest month vs. ET in hottest month

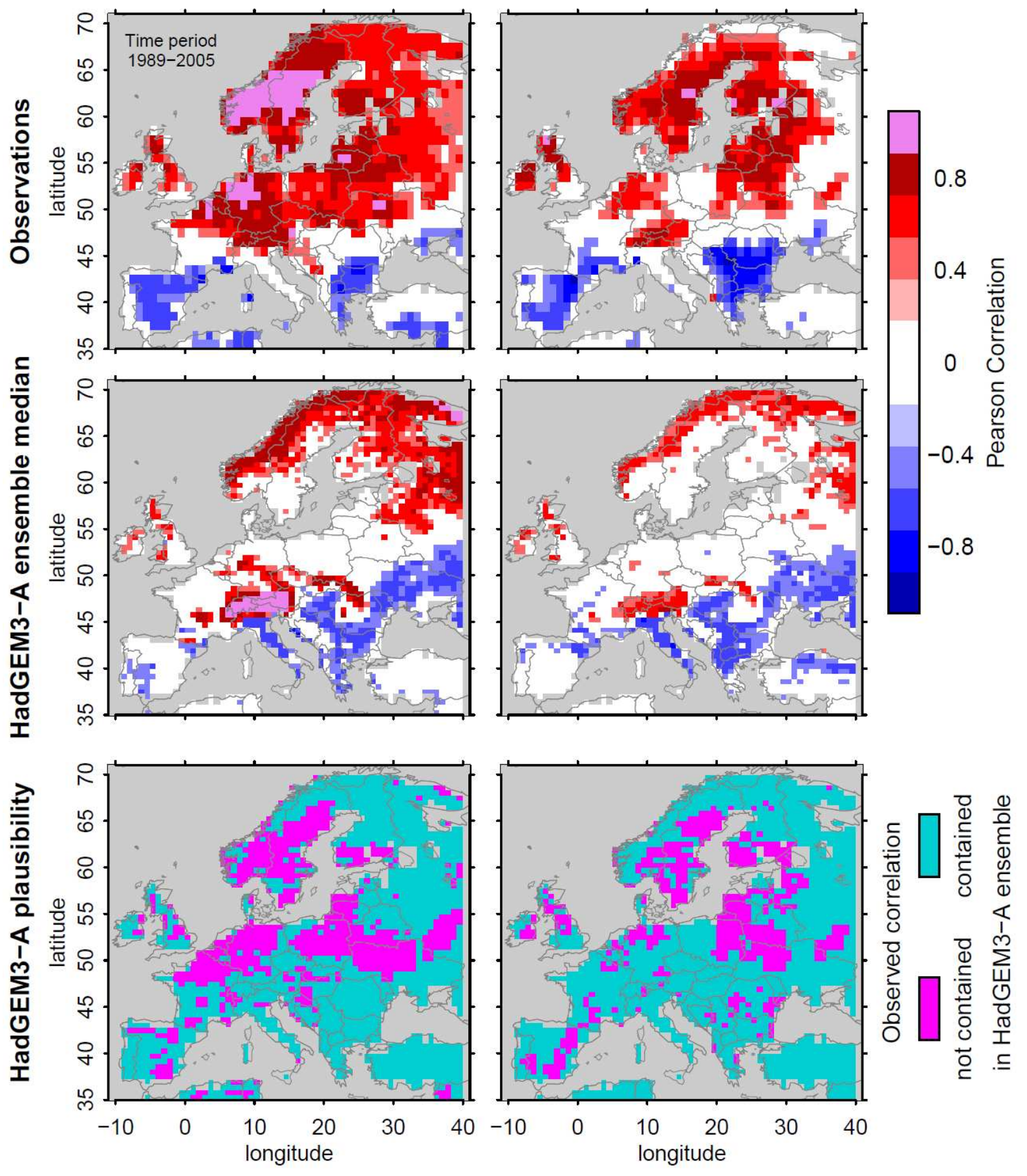


monthly mean T in hottest month TXx in hottest month vs. ET in hottest month
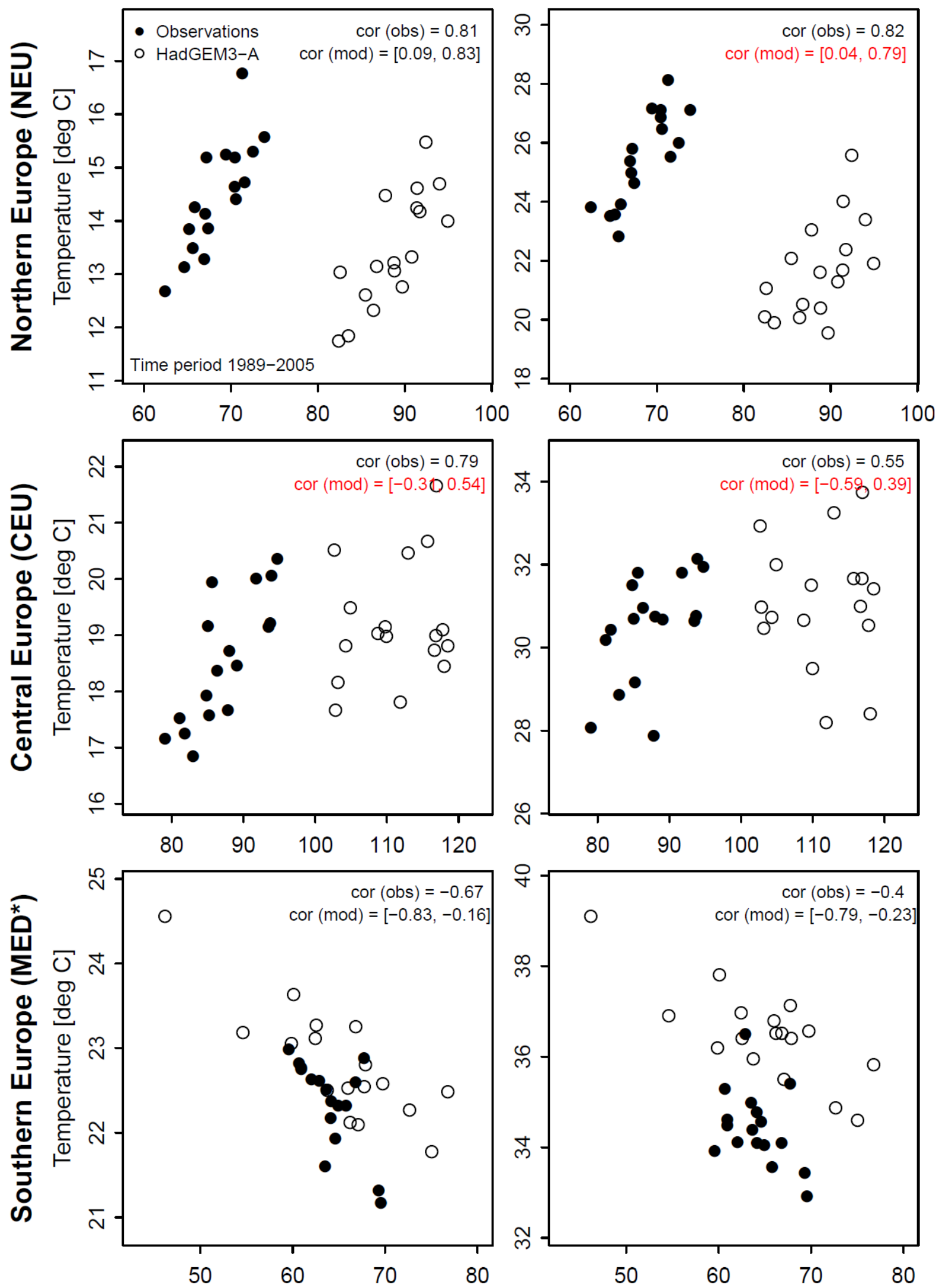

1015

Figure 11 


\section{E-OBS}
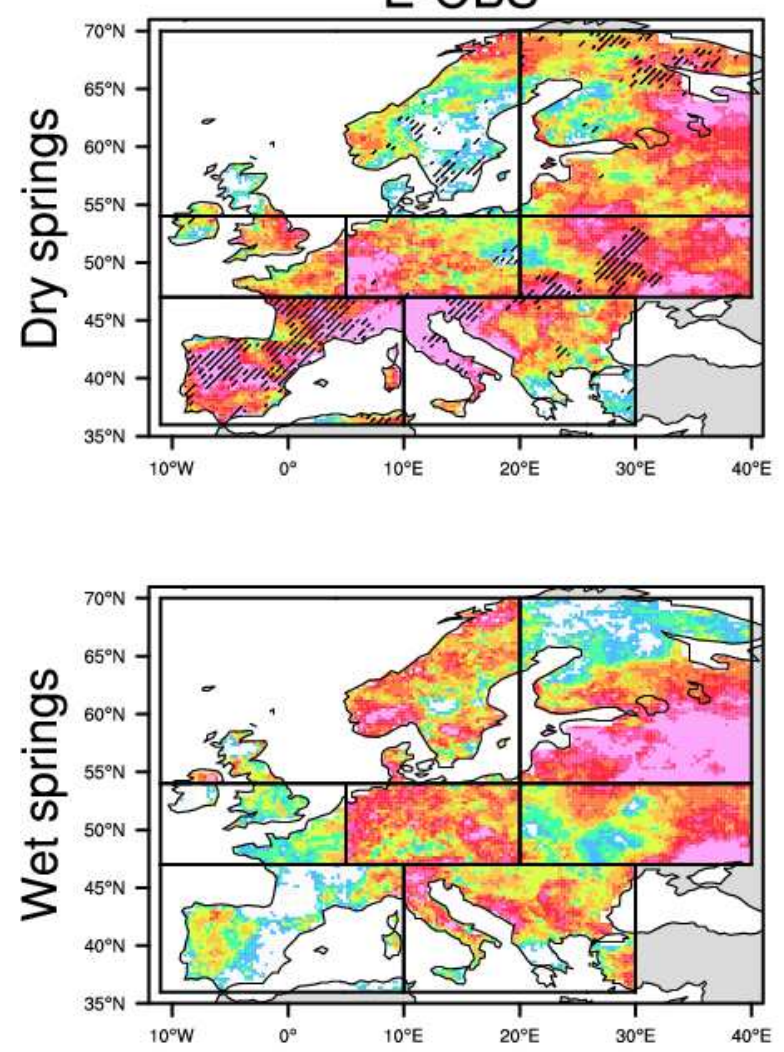
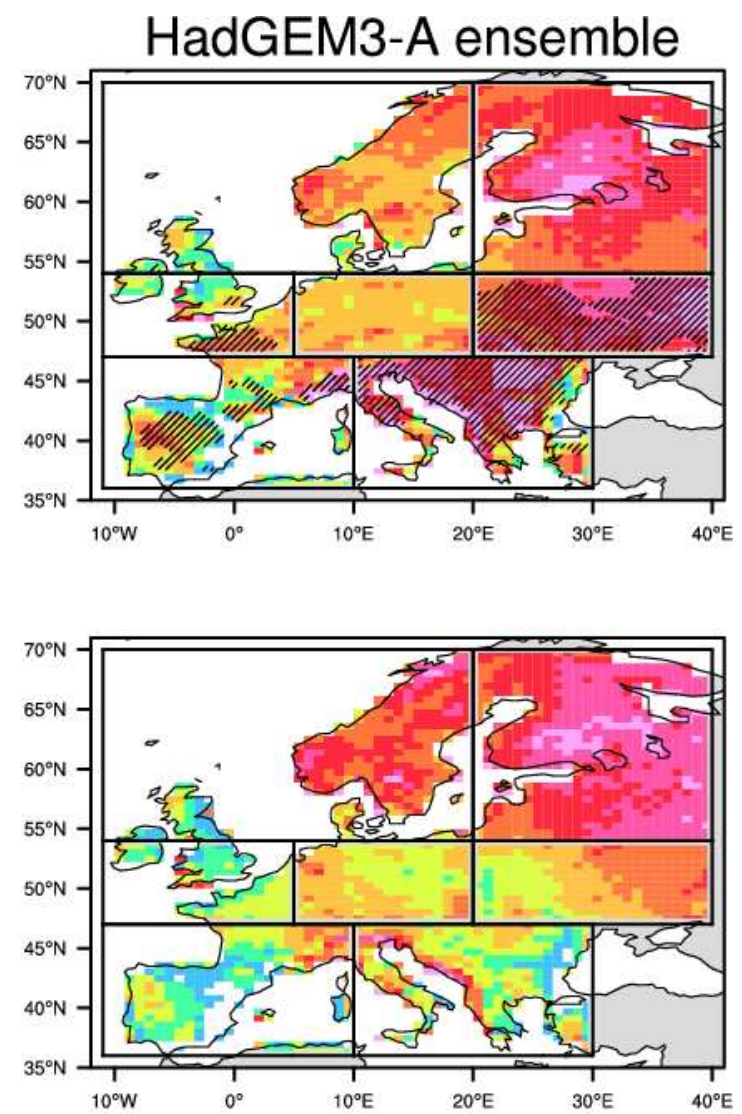

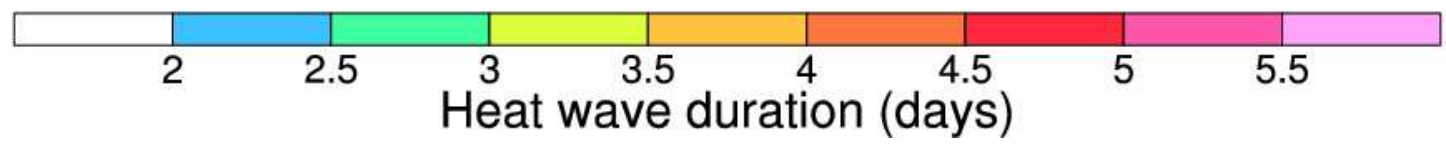

1018 Figure 12
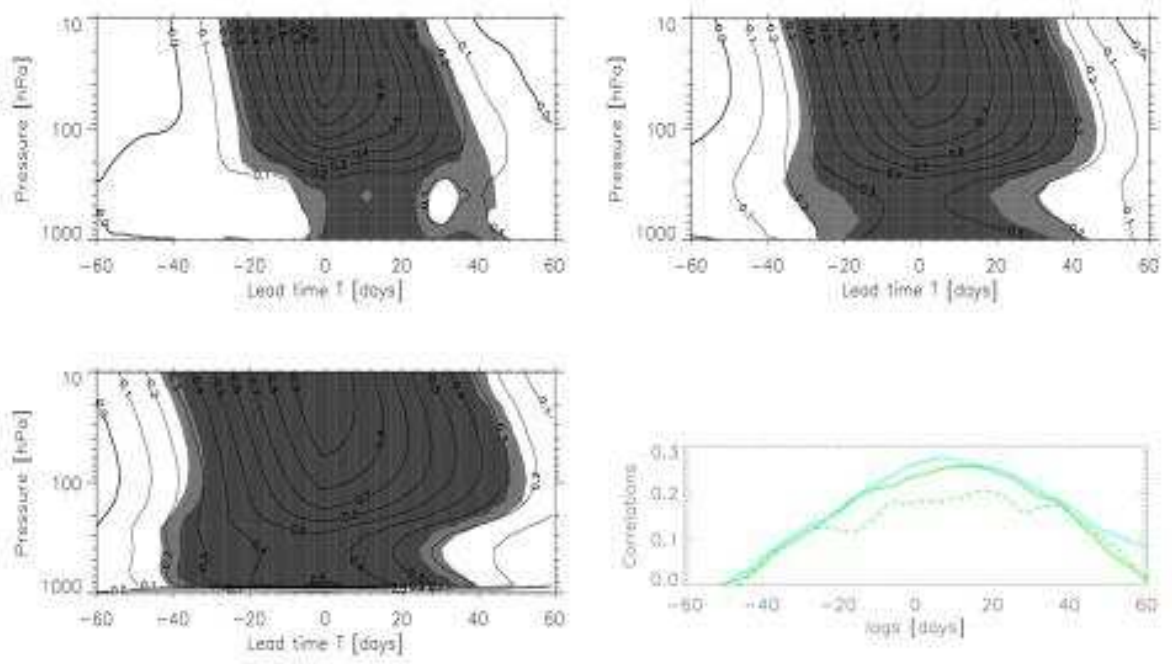

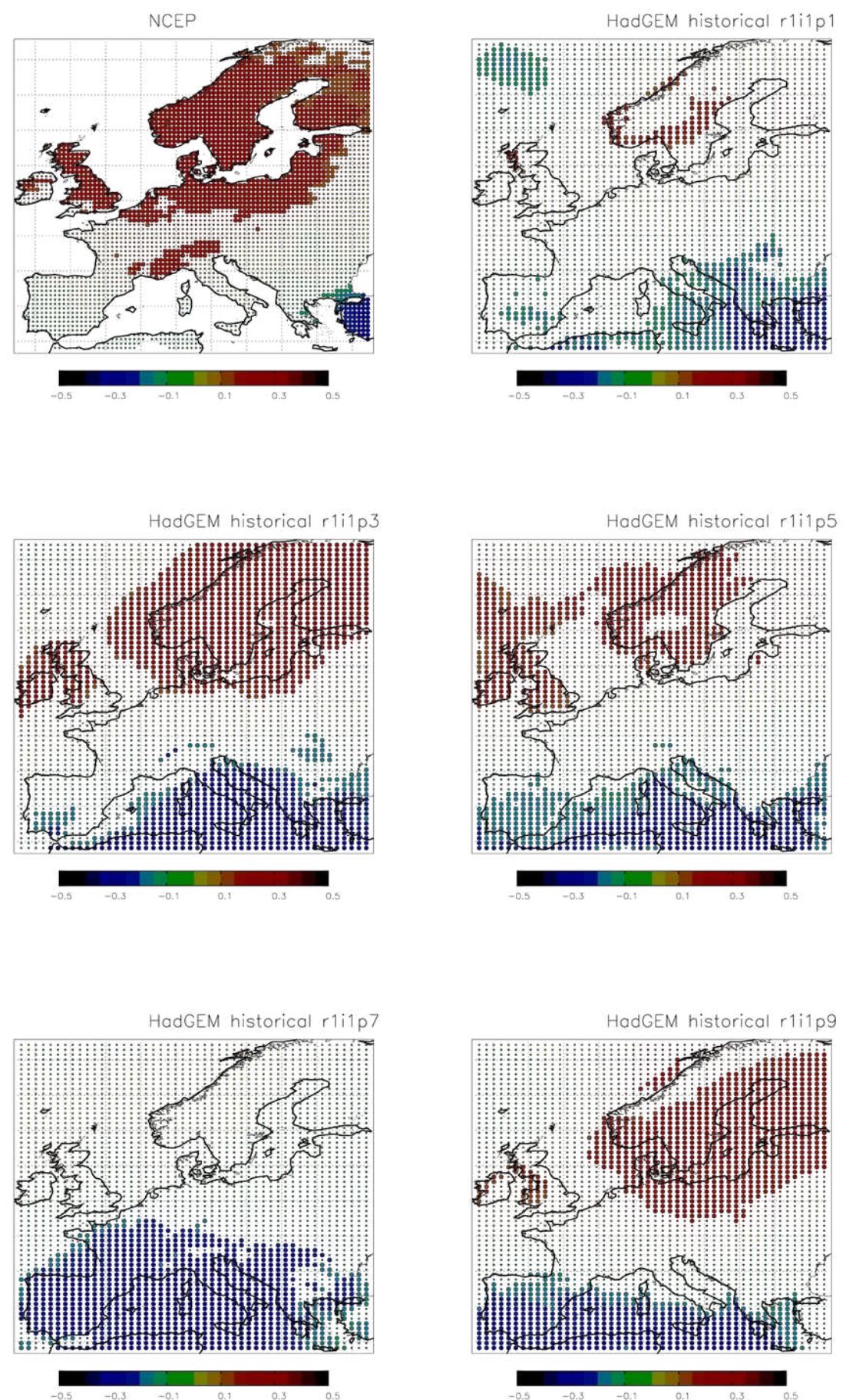

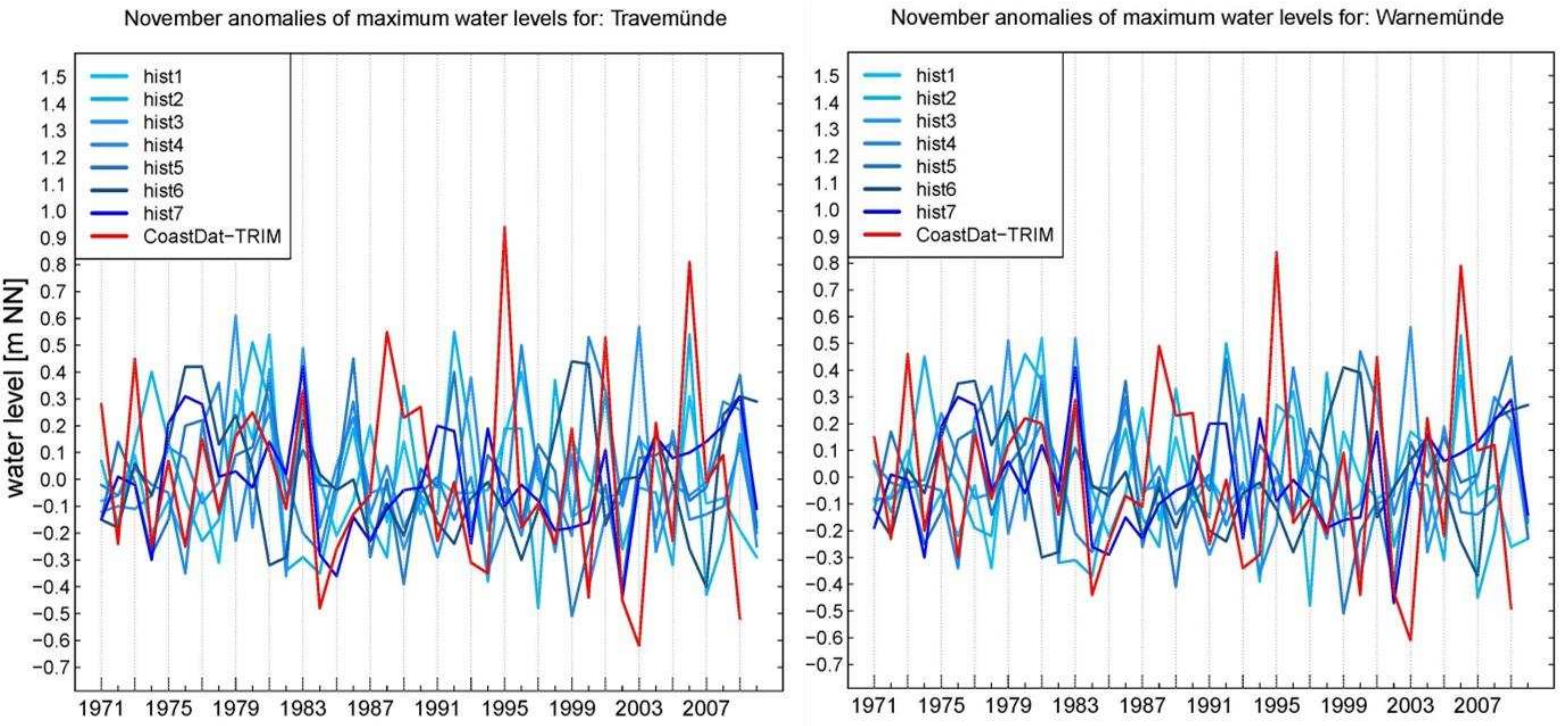

Figure 15

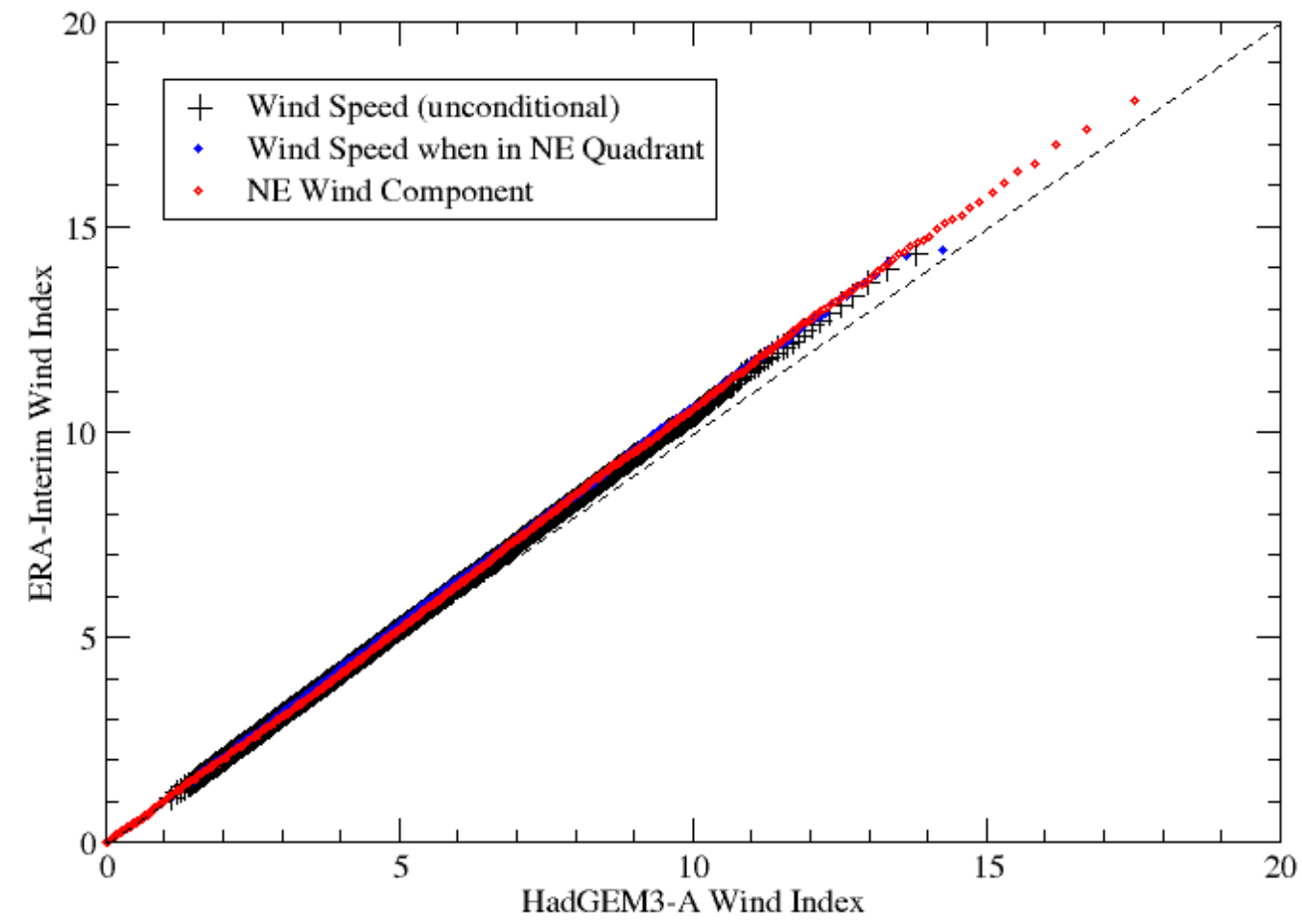

Figure 16 


\begin{tabular}{|c|c|c|c|}
\hline & Dataset & Time period & Spatial Resolution \\
\hline Temperature & $\begin{array}{l}\text { E-OBS v14.0 (Haylock et al. 2008) } \\
\text { CRUTS } 3.23 \text { (UEA 2015) } \\
\text { 20CR reanalysis temperature data, } \\
\text { averaged from 6hrly values }\end{array}$ & $1960-2013$ & $0.5^{\circ} \times 0.5^{\circ}$ \\
\hline Precipitation & $\begin{array}{l}\text { E-OBS v14.0 } \\
\text { (Haylock et al. 2008) }\end{array}$ & $1960-2013$ & $0.5^{\circ} \times 0.5^{\circ}$ \\
\hline Sea level pressure & $\begin{array}{l}\text { NCAR/NCEP reanalyses } \\
\text { NOAA 20CR reanalysis, version 2c }\end{array}$ & $1948-2014$ & $\begin{array}{l}2.5^{\circ} \times 2.5^{\circ} \\
2^{\circ} \times 2^{\circ}\end{array}$ \\
\hline $10-\mathrm{m}$ winds & ERA-Interim reanalysis & $1979-2013$ & $0.7^{\circ} \times 0.7^{\circ}$ \\
\hline Soil Moisture & $\begin{array}{l}\text { SWBM Dataset (Orth and } \\
\text { Seneviratne 2015) }\end{array}$ & $1984-2013$ & $0.5^{\circ} \times 0.5^{\circ}$ \\
\hline Evapotranspiration & $\begin{array}{l}\text { LandFLux-EVAL Dataset (Mueller et } \\
\text { al. 2013) }\end{array}$ & $1989-2005$ & $1^{\circ} \times 1^{\circ}$ \\
\hline
\end{tabular}

Table 1: Overview of employed reference datasets

\begin{tabular}{|l|l|l|l|l|l|l|l|l|}
\hline Regime & $\begin{array}{l}\text { Winter: } \\
\text { AR }\end{array}$ & $\begin{array}{l}\text { Winter: } \\
\text { BLO }\end{array}$ & $\begin{array}{l}\text { Winter: } \\
\text { NAO- }\end{array}$ & $\begin{array}{l}\text { Winter: } \\
\text { ZO }\end{array}$ & $\begin{array}{l}\text { Summer: } \\
\text { AL }\end{array}$ & $\begin{array}{l}\text { Summer: } \\
\text { BLO }\end{array}$ & $\begin{array}{l}\text { Summer: } \\
\text { NAO- }\end{array}$ & $\begin{array}{l}\text { Summer: } \\
\text { AR }\end{array}$ \\
\hline NCEP/NCAR & $24.4 \%$ & $27.2 \%$ & $21.0 \%$ & $27.4 \%$ & $22.6 \%$ & $30.1 \%$ & $21.2 \%$ & $28.6 \%$ \\
\hline $\begin{array}{l}\text { HadGEM3-A } \\
(15 \text { members })\end{array}$ & $23.8 \%$ & $27.0 \%$ & $22.5 \%$ & $26.6 \%$ & $18.5 \%$ & $28.4 \%$ & $24.6 \%$ & $26.2 \%$ \\
\hline
\end{tabular}

Table 2: Weather regime occupancies (or frequencies) for each cluster, clusters being referenced from 1036 the NCEP/NCAR reanalyses, for each season. 

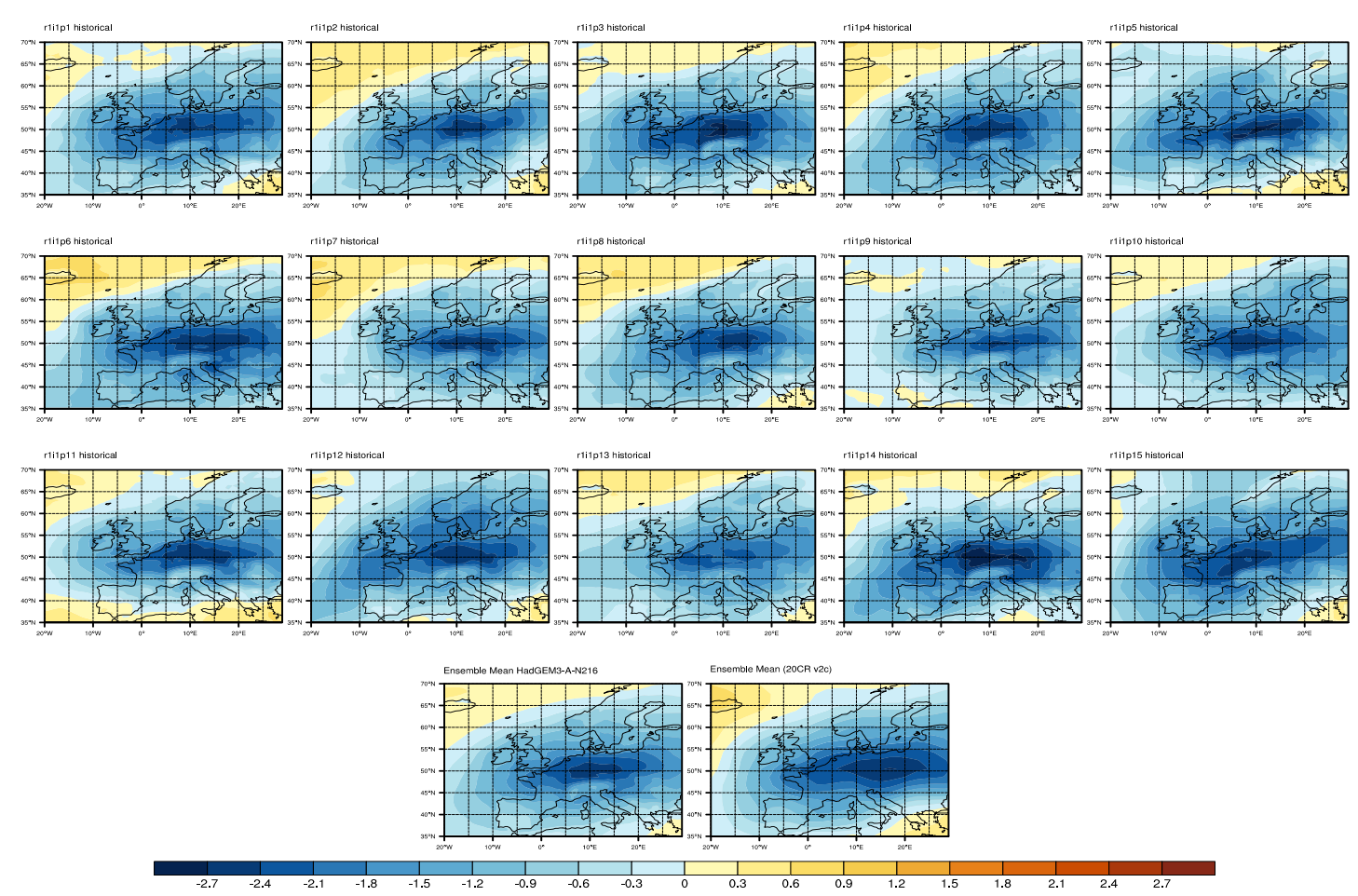

1039 Supplementary Figure 1: DJF Composites of the standardized near-surface temperature for cold winter events over Central Europe in Had-GEM3-N216 historical forcing ensemble members 1-15 (lines 1-3), ensemble mean (line 4, left) and and 20CR ensemble mean (line 4, right). The composites have been derived from all cases where the area-averaged temperature over Central Europe is smaller than its 5th seasonal percentile in DJF. 

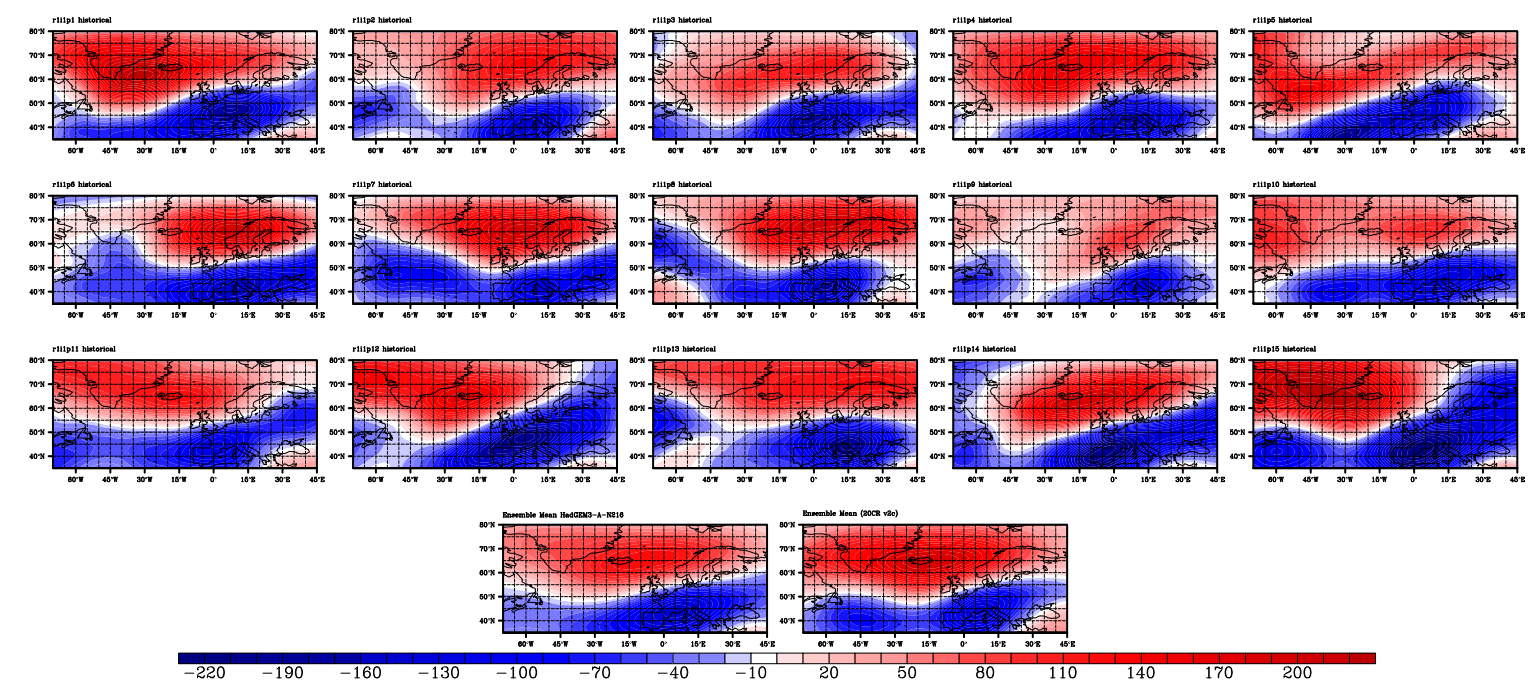

1046

1047 Supplementary Figure 2: DJF Composites of the standardized geopotential height at 500mb for cold 1048 winter events over Central Europe in Had-GEM3-N216 ensemble members 1-15 (lines 1-3), ensemble 1049 mean (line 4, left) and and 20CR ensemble ( line 4, right). The composites have been derived from all 1050 cases where the area-averaged temperature over Central Europe is lower than the 5th seasonal 1051 percentile in DJF of the associated temperature. 